\title{
Aggregation of nanoscale iron oxyhydroxides and corresponding effects on metal uptake, retention, and speciation: II. Temperature and time
}

\author{
Stegemeier, J.P., Reinsch, B.C., Lentini, C.J., Dale, J.G., and Kim, C.S.* \\ Revised submission 8/20/14
}

School of Earth and Environmental Sciences, Schmid College of Science and Technology, Chapman University, Orange, CA 92866

*contact email: cskim@chapman.edu

\section{ABSTRACT}

The aggregation and growth of nanosized particles can greatly impact their capacity to sorb and retain dissolved metals, thus affecting metal fate and transport in contaminated systems. Aqueous suspensions of synthesized nanoscale iron oxyhydroxides were exposed to dissolved $\mathrm{Zn}(\mathrm{II})$ or $\mathrm{Cu}(\mathrm{II})$ and aged at room temperature $\left(\sim 20^{\circ} \mathrm{C}\right), 50^{\circ} \mathrm{C}$, and $75^{\circ} \mathrm{C}$ for timeframes ranging from 0-96 hours before sorbed metal ions were desorbed by lowering the suspension $\mathrm{pH}$. Atomic absorption spectroscopic analysis of supernatants both before and after the desorption step determined how temperature and time affect macroscopic metal uptake and retention capacities. Extended X-ray absorption fine structure (EXAFS) spectroscopy analysis described the local binding environment of the sorbed/retained metals on the solid phase. 
With increasing aging temperature and time, the initial $\sim 5-\mathrm{nm}$ oblong nanoparticles formed dense aggregates, lost reactive surface area, and retained progressively larger fractions of the initially-introduced $\mathrm{Zn}$ (II) and $\mathrm{Cu}$ (II) following the desorption step, with the copper species inhibiting the oriented aggregation of the nanoparticles into nanorods. Based on EXAFS analysis, the speciation of the sorbed metal species evolves with increasing time and temperature from surface-sorbed metal ions, which readily desorb and return to solution, to more stronglybound, structurally-incorporated metal ions. These retained metals appear to associate intimately with the nanoparticle aggregates by substituting for iron in the nanoparticle lattice or by binding within nanoparticle aggregate pore spaces. 


\section{INTRODUCTION}

Iron oxyhydroxides are ubiquitous in the near-surface environment and play a significant role in the fate and transport of metal contaminants, particularly in aqueous systems. As a result, many investigators have characterized the ability of iron oxyhydroxides to sequester dissolved metals from the aqueous phase through adsorption (JEON et al., 2003; KIM et al., 2004;

MANCEAU, 1995; OSTERGREN et al., 2000), surface precipitation (FUKUSHI and SVERJENSKY, 2007; ROBERTS et al., 2003), and coprecipitation (ERBS et al., 2010; MARTINEZ and MCBRIDE, 1998; VIOLANTE et al., 2007) reactions. In contrast, the desorption of adsorbed metals back into solution under natural aqueous conditions has been less extensively studied, yet holds important implications for the long-term retention of metals in the solid phase and the viability of environmental remediation strategies that involve sorption processes (MUSTAFA et al., 2006; SRIVASTAVA, 1990). Studies have also found that iron oxyhydroxides often initially form in natural systems as nanosized particles (PENN et al., 2001; VAN DER ZEE and ROBERTS, 2003), and can be strongly associated with trace metals (PLATHE et al., 2010; Plathe et al., 2013), placing additional emphasis on the need to better characterize metal adsorption to and desorption from nanoscale phases.

Due to their extremely small size, nanoparticles exhibit a number of unique physical and chemical properties (BANFIELD and NAVROTSKY, 2001; GILBERT et al., 2004; KERSTING et al., 1999; NOVIKOV et al., 2006; PENN et al., 2007; VILKS et al., 1997) which can result in the deviation of a nanoscale mineral phase in reactivity, stability, and degree of structural or surface (dis)order relative to micro- or macroscale versions of the same phase (CWIERTNY et al., 2008; MADDEN et al., 2006; PENN et al., 2006). Additionally, under most natural aqueous conditions, nanoparticles tend to aggregate rapidly, with variables such as $\mathrm{pH}$, ionic strength/salinity, temperature, the presence of organic matter, aging time, and drying/rewetting cycles inducing the 
aggregation and compaction of nanoparticles to varying extents (BAALOUSHA, 2009; GILBERT et al., 2009). Under certain conditions this induces oriented attachment of nanoparticles (GUYODO et al., 2003; YUWONO et al., 2010), while at other times a less ordered flocculation of nanoparticles occurs (DALE et al., 2014 (submitted); GILBERT, 2007). Additionally, while aggregation via increases in $\mathrm{pH}$ and ionic strength generates relatively open aggregates containing substantial interstitial water, aggregation by thermal aging and drying significantly reduces interstitial water, inhibits ion transport within aggregates, and facilitates conversion to more ordered mineral and surface structures (GILBERT et al., 2009; KIM et al., 2007; LIU et al., 2009), leading to significant changes in sorption properties. Therefore, in most cases the aggregation of nanoparticles influences metal binding and retention processes and correspondingly the mobility of potentially toxic metals in the environment (DALE et al., 2014 (submitted); GILBERT et al., 2009; HochELlA, 2002; KIM et al., 2008). Results from the first part of this two-part study, for example, demonstrate that iron oxyhydroxide nanoparticle aggregation by increased $\mathrm{pH}$ or ionic strength reduces the initial uptake yet enhances the retention of dissolved zinc ions (DALE et al., 2014 (submitted)).

This most recent study as well as past sorption studies suggest that iron oxyhydroxides feature multiple binding sites for specific metal(loid)s, with binding affinity being greatly substrate- and metal(loid)-dependent (BENJAMIN and LECKIE, 1981; TRIVEDI and AXE, 2001a; VENEMA et al., 1996). Kinetic uptake studies frequently observe biphasic uptake behavior for various metal(loid)s (CARABANTE et al., 2009; YIN et al., 1997). The initial uptake phase typically involves rapid adsorption associated with the immediate formation of outer- and innersphere surface complexes (GROSSL and SPARKS, 1995), while the second uptake phase occurs more slowly, a process that has been attributed to a variety of mechanisms including diffusion into micropores (TRIVEDI and AXE, 2000; TRIVEDI and AXE, 2001b), (co-)precipitation or surface 
precipitation (DAVIS et al., 1987; SAHAI, 2007), adsorption to more weakly-binding surface sites (BENJAMIN and LECKIE, 1981), and structural incorporation or substitution into the substrate lattice (AlvareZ et al., 2007; AlvarEZ et al., 2005). However, these mechanisms have not yet been thoroughly applied to describe metal uptake to nanoscale particles or aggregates of nanoparticles.

This study investigates the effects of different aggregation mechanisms on the adsorption, desorption, and retention behavior of metals associated with iron oxyhydroxide nanoparticles by pairing macroscopic batch adsorption/desorption experiments with extended X-ray absorption fine structure (EXAFS) spectroscopy to quantify the extent of metal uptake and retention and to identify the mode(s) of metal binding, respectively. Nanoparticle aggregation induced by increases in temperature and time are examined in this, the second of the two-part study, with the first part focusing on aggregation as a function of $\mathrm{pH}$ and ionic strength (DALE et al., 2014 (submitted)). Specifically, this study explores the sorption and retention properties of $\mathrm{Zn}(\mathrm{II})$ and $\mathrm{Cu}(\mathrm{II})$ onto iron oxyhydroxide nanoparticles while being thermally aged at different temperatures over time. The more extensive aggregation/growth of nanoparticles through heating compared to $\mathrm{pH}$ - and ionic strength-based aggregation will allow comparison across a wider range of nanoparticle aggregation states and specifically investigate whether larger changes in adsorbed metal speciation occur, compared to the relatively subtle shifts observed in the earlier study.

\section{METHODS}

\subsection{Nanoparticle synthesis}

A suspension of iron oxyhydroxide nanoparticles was synthesized using an established flash microwave technique (GUYODO et al., 2003) described in greater detail in the first part of 
this study (DALE et al., 2014 (submitted)). Briefly, equal volumes of $0.25 \mathrm{M}$ sodium bicarbonate and $0.20 \mathrm{M}$ ferric nitrate were mixed, heated in a conventional kitchen microwave until reaching a boil, and then immediately submerged the heated solution into an ice bath, quenching the nucleation reaction.

The resulting nanoparticle suspension ( $2 \mathrm{~L}$ total volume) was then transferred to segments of $1000 \mathrm{MWCO}$ dialysis tubing and placed into a $30 \mathrm{~L}$ tub of deionized water. The DI water was replaced at least three times a day over the course of three days, with $\mathrm{pH}$ and conductivity measured before each replacement to track the removal of excess dissolved constituents. Once $\mathrm{pH}$ and conductivity had stabilized, the dialyzed suspension (final $\mathrm{pH}: 4.13$ ) was transferred into $1 \mathrm{~L}$ HDPE bottles and stored at $4^{\circ} \mathrm{C}$ to be used for sorption experiments within one week of synthesis.

Separate series of thermally aged nanoparticles were prepared for BET surface area and dynamic light scattering analysis by placing aliquots of the initial suspension at room temperature $\left(\sim 20^{\circ} \mathrm{C}\right)$ or into separate ovens set to $50^{\circ} \mathrm{C}$ and $75^{\circ} \mathrm{C}$. Aliquots were collected at the three temperature settings at designated sampling times of $0,1,2,4,12,24,48,72$, and 96 hours and returned to $4^{\circ} \mathrm{C}$ refrigeration.

\subsection{Characterization of initial and aged nanoparticles}

Gravimetric analysis of the initial nanoparticle suspension yielded a solids concentration of $6.7 \pm 0.2 \mathrm{~g} / \mathrm{L}$. Portions of the initial and aged nanoparticle suspensions were air-dried, powdered with a mortar and pestle, and analyzed for $\mathrm{N}_{2}$-reactive surface area using a BeckmanCoulter SA3100 BET surface area analyzer. Transmission electron microscopy analysis was conducted on the initial and select aged nanoparticles using a FEI/Philips CM-20 conventional 
transmission electron microscope. Dynamic light scattering (DLS) analysis was conducted on the control nanoparticles and aged suspensions using a Beckman Coulter Delsa Nano C dynamic light scattering system. Samples were diluted 10x in DI water for optimal particle detection by DLS, mixed thoroughly before analysis, and then analyzed with a $50 \mu \mathrm{m}$ laser aperture size to determine average hydrodynamic diameter and polydispersity.

\subsection{Metal sorption experiments}

Batch macroscopic adsorption/desorption experiments were conducted by adding $100 \mathrm{~mL}$ of $5 \mathrm{mM} \mathrm{Zn}\left(\mathrm{NO}_{3}\right)_{2}$ or $\mathrm{Cu}\left(\mathrm{NO}_{3}\right)_{2}$ to $666 \mathrm{~mL}$ of the initial (control) synthesized nanoparticle suspension. The background electrolyte concentration of the suspension was subsequently adjusted to achieve a final ionic strength of $0.001 \mathrm{M}$ using $0.1 \mathrm{M} \mathrm{NaNO}_{3}$ stock solution. The $\mathrm{pH}$ of each suspension was then adjusted using $1 \mathrm{~mL}$ aliquots of $0.1 \mathrm{M} \mathrm{NaOH}$ to the optimal adsorption $\mathrm{pH}$ values of 6.8 for $\mathrm{Zn}(\mathrm{II})$ and 6.5 for $\mathrm{Cu}(\mathrm{II})$. The adsorption and desorption $\mathrm{pH}$ values for each metal were selected to maximize their uptake and removal from the nanoparticles, respectively, as determined from preliminary macroscopic uptake curves generated earlier using the control nanoparticle suspension. The solution was brought up to a final volume of $1.00 \mathrm{~L}$ with a $0.001 \mathrm{M} \mathrm{NaNO}_{3}$ solution, resulting in a final solids concentration of $4.5 \mathrm{~g} / \mathrm{L}$ and $\mathrm{Zn}$ (II) or $\mathrm{Cu}(\mathrm{II})$ concentration of $0.5 \mathrm{mM}$. The experimental conditions achieved a $\mathrm{Zn} /(\mathrm{Zn}+\mathrm{Fe})$ ratio of 0.001 , between $4-130$ times lower than those of the adsorption and coprecipitation experiments of Waychunas et al. investigating $\mathrm{Zn}$ (II) on ferrihydrite (WAYCHUNAS et al., 2002); this suggests that (co)precipitation was unlikely to occur in our system.

The suspensions were then split into pairs of $10 \mathrm{~mL}$ aliquots in $15 \mathrm{~mL}$ Falcon tubes and either retained at room temperature $\left(\sim 20^{\circ} \mathrm{C}\right)$ or placed into separate ovens set to $50^{\circ} \mathrm{C}$ and $75^{\circ} \mathrm{C}$. 
Aliquot pairs were collected at all three temperature settings at designated sampling times of 0 , $1,2,4,12,24,48,72$, and 96 hours. One aliquot from each pair was immediately set aside at each designated sampling time and is hereafter referred to as the "adsorbed" sample.

Metal desorption from the nanoparticles was induced by bringing the second of the two $10 \mathrm{~mL}$ aliquots, hereafter referred to as the "desorbed" sample, to its respective desorption $\mathrm{pH}$ value as determined from preliminary macroscopic sorption curves: 5.0 for $\mathrm{Zn}(\mathrm{II})$ and 4.2 for

$\mathrm{Cu}(\mathrm{II})$. The target $\mathrm{pH}$ values were achieved through the progressive addition of $10 \mu$ aliquots of $0.1 \mathrm{M} \mathrm{HNO}_{3}$ and maintained for a period of 30 minutes. Trial experiments in which desorption was allowed to proceed for 90 minutes showed no significant difference in desorbed metal concentrations compared to the 30 minute sample, thus 30 minute desorption times were concluded to be sufficient. Both adsorbed and desorbed samples were then centrifuged at 3000 RPM for 10 minutes. The supernatants were decanted, filtered using a $0.20 \mu \mathrm{m}$ nylon filter, and acidified with $20 \mu$ aliquots of $70 \% \mathrm{HNO}_{3}$ to $\mathrm{pH}<2.0$ prior to dissolved metal analysis (Fe and $\mathrm{Zn}$ or $\mathrm{Cu}$ ) using a Thermo Solaar S4 atomic absorption spectrometer. The remaining solid pellets were collected and excess water wicked away using Whatman filter paper before loading the samples as damp pastes into $1.5 \mathrm{~mm}$-thick slotted Teflon holders and sealing with Kapton tape for EXAFS spectroscopy analysis. Supernatants and solid pellets were stored at $4^{\circ} \mathrm{C}$ until analysis.

\subsection{EXAFS collection and analysis}

EXAFS K-edge fluorescence spectra of Zn $(9659 \mathrm{eV})$ and $\mathrm{Cu}(8979 \mathrm{eV})$ were collected at wiggler magnet beamline 11-2 at the Stanford Synchrotron Radiation Lightsource (SSRL) using a high throughput 32-element Ge detector which allows better resolution of low-concentration 
samples compared to transmission- or ion chamber-collected data (WAYCHUNAS and BROWN, 1994). The damp solid sample pellets were analyzed at room temperature using aluminum filters and Soller slits to reduce iron fluorescence and elastic scattering, respectively. Zinc and copper metal foils were placed between ion chambers positioned downstream from the sample and used as standards to calibrate the monochromator energy for each scan.

EXAFS spectra were analyzed using the SixPack analysis software v0.64 (WEBB, 2005). A deadtime curve was collected and deadtime correction applied to the data to adjust for potential oversaturation of specific channels within the detector. All spectra were energy calibrated using the calibration foils and averaged prior to conducting shell-by-shell fitting of the $\mathrm{k}^{3}$-weighted chi functions over $\mathrm{k}$ ranges of $2.75-11.75 \AA^{-1}$ for zinc and $3.0-9.5 \AA^{-1}$ for copper. Model single shell scattering paths were created using FEFF 61 (REHR and ALBERS, 2000) based upon literature-derived $\mathrm{Zn}-\mathrm{O}, \mathrm{Zn}-\mathrm{Fe}, \mathrm{Cu}-\mathrm{O}, \mathrm{Cu}-\mathrm{Fe}$, and $\mathrm{Cu}-\mathrm{Cu}$ distances from similar sorption systems (LiN et al., 2004; PEACOCK and Sherman, 2004; Trivedi et al., 2001; WAYChUNAS et al., 2002). The scale factor $\left(S_{0}\right)$ was fixed at 0.9 for all samples and the Debye-Waller factor $\left(\sigma^{2}\right)$, which serves as a measure of thermal vibration and static disorder around the target metal in the sample, was allowed to float for first-neighbor shells. For second-neighbor shells, the DebyeWaller factor was set at fixed values in order to directly compare second-neighbor fitting results between samples; these values were determined from past experience with comparable sorption systems and by averaging values resulting from spectral fits in which the second-shell DebyeWaller factors were allowed to float.

\section{RESULTS}

\subsection{Initial and aged nanoparticle characterization}

4.1.1. Transmission electron microscopy 
TEM images of the initial nanoparticles confirmed a predominately monodisperse suspension of $\sim 5 \mathrm{~nm}$ oblong spheroidal particles and some rod-like particles (Fig. 1) consistent with those observed by others using the same synthesis method (GUYODO et al., 2003;

WAYCHUNAS et al., 2005). A relatively minor degree of aggregation is visible in the form of the oriented nanorods, which may have been induced during the drying of the particles on the TEM sample grid. TEM images of the nanoparticles after thermal aging at $75^{\circ} \mathrm{C}$ for 96 hours in the absence of metals appear primarily as dense clusters of individual 3-5 $\mathrm{nm}$ oblong particles with regular occurrence of larger, more ordered crystals in the form of 20-40 nm long rods (Fig. 1b). Oriented attachment of the initial spheroidal nanoparticles generates elongated nanorods consistent with the normal acicular morphology of goethite (GUYODO et al., 2003; WAYCHUNAS et al., 2005). The transition from spheroidal nanoparticles to more ordered, faceted rods is likely to result in a general increase in surface ordering and reactive behavior more regularly consistent with goethite than less-ordered phases such as ferrihydrite.

The nanoparticle sample aged in the presence of $\mathrm{Zn}(\mathrm{II})$ also features a significant proportion of these acicular, rod-shaped particles (Fig. 1c), suggesting that Zn(II) either facilitates or at least does not interfere with the formation of the nanorods. In contrast, nanoparticles aged in the presence of $\mathrm{Cu}(\mathrm{II})$ appear as agglomerates of individual spheroidal particles with only sparse occurrence of nanorods (Fig. 1d). Based on this and our previous Xray diffraction studies of iron oxyhydroxide nanoparticles aged under similar conditions (KIM et al., 2008; WAYCHUNAS et al., 2005), the presence of $\mathrm{Cu}(\mathrm{II})$ appears to retard the growth and structural ordering of the initial nanoparticles towards more ordered goethite nanorods while the presence of Zn(II) does not. Specifically, these findings agree with our prior work using X-ray diffraction peak intensities to track the crystallinity of nanoparticulate goethite with increasing aging times in the presence of various metal(loid)s (Fig. 2), where the evolution over time of X- 
ray diffraction peaks consistent with goethite is slowed in the presence of dissolved $\mathrm{Cu}(\mathrm{II})$ (KIM et al., 2008). Such inhibition may occur, in the case of $\mathrm{Cu}(\mathrm{II})$, through surface sorption and passivation at sites/faces preferentially involved in oriented aggregation. Additionally, no other peaks corresponding to (co-)precipitated zinc or copper species were detected, indicating that $\mathrm{Zn}$ or $\mathrm{Cu}$ precipitation was not a major process.

\subsubsection{Particle size and surface area analysis}

Average particle diameter as determined through dynamic light scattering increased systematically as a function of both temperature and time (Fig. 3). The samples aged at $75^{\circ} \mathrm{C}$ experienced the greatest increase in particle diameter, most significantly after 24 hours of aging. Increases in particle size were accompanied by corresponding reductions in specific surface area as measured using nitrogen adsorption (Fig. 3). After four days of aging the particles at room temperature, the average particle size and surface area did not significantly change from the initial $\sim 10 \mathrm{~nm}$ diameter particles with $\sim 275 \mathrm{~m}^{2} / \mathrm{g}$. This finding agrees with our previous studies (WAYCHUNAS et al., 2005) indicating that the loss of specific surface area is a direct result of the change in particle size due to temperature-induced nanoparticle growth through aggregation and/or ripening.

\section{2. $\mathrm{Zn}(\mathrm{II})$ sorption and retention}

\subsubsection{Macroscopic adsorption/desorption batch experiments}

At all temperatures and time intervals sampled, the "adsorbed" aliquots exhibited $\geq 97 \%$ uptake of $\mathrm{Zn}(\mathrm{II})$, indicating that macroscopic sorption of $\mathrm{Zn}(\mathrm{II})$ by the nanoparticles is both rapid (occurring in $\leq 1$ hour) and effectively complete under the experimental conditions examined (Fig. 4). Using the initial nanoparticle surface area generated from BET measurements, this 
results in a initial maximum $\mathrm{Zn}$ (II) surface coverage of $\sim 1.8 \mu \mathrm{mol} / \mathrm{m}^{2}$, which is in the range of the documented maximum surface saturation range of $1-2 \mu \mathrm{mol} / \mathrm{m}^{2}$ (HIEMSTRA et al., 2010; VILLALOBOS et al., 2003) above which surface precipitation becomes a concern.

More distinct differences in the macroscopic behavior of $\mathrm{Zn}(\mathrm{II})$ at the different aging temperatures/times are observed among the "desorbed" aliquots, with Fig. 4 also plotting Zn(II) retention to the nanoparticles after the desorption step (as a percentage of the initial amount of $\mathrm{Zn}(\mathrm{II})$ introduced) versus aging time. The proportion of $\mathrm{Zn}(\mathrm{II})$ retention after the desorption step progressively increases as a function of both temperature and time, suggesting that at higher temperatures, larger fractions of metal ions associate with the substrate at strongly-binding surface sorption sites or within the nanoparticle aggregates, inhibiting desorption and increasing retention. This trend is significant in light of the prior observation that the surface area of the particles declines with time and temperature, suggesting that simple surface reactivity is not sufficient to explain the sorption and retention behavior in these experiments.

At all temperatures, the percentages of $\mathrm{Zn}(\mathrm{II})$ retained by the nanoparticles rapidly increase within the first 12-24 hours, decline between 24 and 48 hours, and subsequently increase again out to 96 hours at a slower rate than the initial uptake stage. This macroscopic uptake/retention behavior suggests a transition between $\mathrm{Zn}$ sorption mechanisms/modes over time; for example, initial and rapid adsorption as outer-sphere or surface sorption complexes may be followed by later migration or incorporation into the substrate's crystalline structure. The decline in $\mathrm{Zn}(\mathrm{II})$ retention between $24-48$ hours, which was found to be repeatable in duplicate trials, may represent the desorption of a fraction of the surface-sorbed $\mathrm{Zn}$ (II) during the formation of nanorods from the initial oblong nanoparticles by oriented aggregation, followed by resumed uptake and retention to the newly-formed nanorods with increasing time. 


\subsubsection{EXAFS analysis}

\subsubsection{Effect of desorption step and aging time on $\mathrm{Zn}$ speciation}

Fig. 5 plots experimental and fitted Zn K-edge EXAFS spectra and their corresponding Fourier transforms (FT) for representative $\mathrm{Zn}$ adsorption and desorption pairs aged at $75^{\circ} \mathrm{C}$. In each of the three adsorption/desorption pairs (i.e. at 4, 24, and 96 hours aging time), visible changes in the EXAFS oscillations, notably between 5-7 $\AA^{-1}$ and 7-9 $\AA^{-1}$, correspond with increasing amplitude of the second-neighbor FT features after the desorption step. Specifically, the amplitude of the shortest of the second-neighbor FT features consistently increases the most, while the amplitude of the most distant second-neighbor feature appears to be less affected by the desorption process. Additionally, these second-neighbor features progressively increase in intensity with aging time, whether comparing the adsorbed spectra or the desorbed spectra with one another at the different time intervals. Fitting was not conducted on the low-intensity features beyond the second-neighbor features $(>3.5 \AA)$ as they are likely a result of or can be obscured by the significant noise in the EXAFS spectra due to low Zn concentrations in the samples.

Quantitative Zn EXAFS shell-by-shell fitting results (Table 1) show that coordination numbers $(\mathrm{CNs})$ of the desorbed sample fits are generally greater than those of the corresponding adsorbed sample fits (indicated by the parameter $\bullet_{\mathrm{CN}-\mathrm{AD}}$ representing the $\%$ change in $\mathrm{CN}$ ), consistent with the qualitative observations of the EXAFS and FTs mentioned earlier. Such differences between the adsorbed and desorbed samples are expected to be both real and significant when considered in conjunction with the visible qualitative changes observed in the raw EXAFS spectra and FTs, even though the increases in CN statistically fall within the 
associated errors. First-shell fitting results also show a progressive lengthening of the $\mathrm{Zn}-\mathrm{O}$ interatomic distance, i.e. from $1.95 \pm 0.01 \AA$ (adsorbed, 4 hrs) to $2.05 \pm 0.01 \AA$ (desorbed, 96 hrs). The increases in both $\mathrm{Zn}-\mathrm{O}$ coordination numbers and $\mathrm{Zn}-\mathrm{O}$ interatomic distances are consistent with a slightly increased proportion of octahedrally-coordinated $\mathrm{Zn}$, as reported by other investigators (JUILLOT et al., 2008; TRAINOR et al., 2000; TRIVEDI et al., 2001; WAYCHUNAS et al., 2002), although tetrahedral coordination with oxygen appears to remain the dominant coordination chemistry across all samples.

The second-shell fits remain fixed at relatively constant interatomic distances over time but increase in $\mathrm{CN}$ after the desorption step, consistent with the observed changes in the secondneighbor FT features. All second neighbors were fit best with Zn-Fe scattering paths as fits attempted using $\mathrm{Zn}-\mathrm{O}$ and $\mathrm{Zn}-\mathrm{Zn}$ scattering paths yielded lower-quality fits. The percentage change in $\mathrm{Zn}-\mathrm{Fe} \mathrm{CN}$ between the adsorbed and desorbed samples, while still indicating a positive change, also generally decreases with interatomic distance within a given sample. This may indicate a shift in the proportion of $\mathrm{Zn}$ sorption modes as a result of the desorption step or may be a manifestation of a general decline in Fourier transform intensity (and thus in change in intensity) with increasing radial distance. Finally, the absolute $\mathrm{Zn}-\mathrm{Fe} \mathrm{CN}$ values observed in the desorption samples consistently increase with time, suggesting that the dominant mode of $\mathrm{Zn}$ (II) sorption involves progressively greater coordination with neighboring Fe atoms.

The EXAFS fitting results from these experiments can be compared with earlier EXAFS studies by other investigators examining Zn(II) uptake to bulk Fe-hydroxides in order to help identify and eliminate possible $\mathrm{Zn}$ speciation options. For example, the combinations of coordination numbers and interatomic distances obtained through this EXAFS fitting do not match well with past experimenters' EXAFS analyses of model reference compounds including $\mathrm{ZnO}$ (zincite), $\mathrm{ZnCO}_{3}$ (smithsonite), $\mathrm{Zn}_{5}(\mathrm{OH})_{6}\left(\mathrm{CO}_{3}\right)_{2}$ (hydrozincite), and amorphous $\mathrm{Zn}$ - 
hydroxides (TRIVEDI et al., 2001; WAYCHUNAS et al., 2002), nor are they consistent with spectra previously collected on aqueous $\mathrm{Zn}\left(\mathrm{NO}_{3}\right)_{2}$ and crystalline $\alpha \mathrm{Zn}(\mathrm{OH})_{2}$ (not shown). Considering also the previously-mentioned low $\mathrm{Zn} /(\mathrm{Zn}+\mathrm{Fe})$ ratio, sub-monolayer surface coverages of the experiments, and improved fit quality by using $\mathrm{Zn}-\mathrm{Fe}$ instead of $\mathrm{Zn}-\mathrm{Zn}$ second-shell neighbors, we conclude that surface (co)-precipitation does not play a significant role in the speciation of $\mathrm{Zn}$ in the samples.

The observed increase in $\mathrm{Zn}-\mathrm{O}$ coordination number and interatomic distance, indicating a shift from dominantly tetrahedral towards octahedral $\mathrm{Zn}$ coordination, suggests a transition in primary uptake mode from tetrahedrally-coordinated zinc sorption complexes on metal oxide mineral surfaces (TRIVEDI et al., 2001) to either octahedrally-coordinated zinc sorption complexes (NACHTEGAAL and SpaRKS, 2004), ion substitution of zinc into iron hydroxides (MANCEAU et al., 2000) or free hexaaquo Zn(II) species. The macroscopic data showing complete zinc uptake after the adsorption step and substantial retention after the desorption step indicates that the two former possibilities are more likely than the presence of significant proportions of free aqueous $\mathrm{Zn}(\mathrm{II})$.

Juillot et al. used EXAFS spectroscopy to differentiate between Zn(II) sorbed in a tetrahedrally-coordinated form as a mononuclear bidentate corner-sharing surface complex to ferrihydrite (Zn-O: $\mathrm{CN}=3.2$ at $1.96 \AA$, Zn-Fe: $\mathrm{CN}=1$ at $3.47 \AA$ ) and $\mathrm{Zn}$ (II) sorbed octahedrally in both mononuclear bidentate edge-sharing and mononuclear bidentate corner-sharing modes to goethite (Zn-O: CN=4.6 @ 2.06 ̊̊, Zn-Fe: CN=0.9 @ $3.07 \AA$ and 0.8 @ $3.26 \AA$ ) (JuILLOT et al., 2008). Examples of these sorption configurations are shown schematically in Fig. 6c-e; the reader is also referred to Waychunas et al. for a complete representation of all potential $\mathrm{Zn}$ (II) sorption, coprecipitation, and model compound structures (WAYCHUNAS et al., 2002). The 
aforementioned distances compare favorably with those of this study, indicating that surface sorption plays a significant (initial) role in $\mathrm{Zn}$ (II) uptake to Fe-oxyhydroxide nanoparticles and that sorption to both ferrihydrite-like and goethite-like sites are possible. However, several ZnFe CNs reported in this study, particularly those at greater aging times, exceed those typically associated with surface sorption (e.g. inner-sphere bidentate) complexes $\left(\mathrm{CN}_{\mathrm{Zn}-\mathrm{Fe}}=1-2\right)$. Instead, the presence of $\mathrm{Zn}-\mathrm{Fe}$ coordination numbers of 2.0 or greater at multiple distances is suggestive of structural incorporation of zinc into the nanoparticle aggregate structure over time. Additionally, the three $\mathrm{Zn}-\mathrm{Fe}$ interatomic distances reported in this study are comparable to both the $\mathrm{Zn}$-Fe interatomic distances reported by Manceau et al. in samples where Zn substitutes directly for Fe in the goethite structure $(3.00,3.23$, and $3.44 \AA$ with coordination numbers of 1.9, 2.8, and 2.1 respectively (MANCEAU et al., 2000)) and the interatomic Fe-Fe distances within goethite of 3.01, 3.28, and $3.46 \AA$ with coordination numbers of 2, 2, and 4, respectively, as measured using CrystalMaker v7.2.0 (CRYSTALMAKER, 2006).

Based on the identified similarities in $\mathrm{Zn}-\mathrm{Fe}$ interatomic distances, the observed increases in $\mathrm{Zn}-\mathrm{O}$ interatomic distance, and the progressive increase in $\mathrm{Zn}-\mathrm{O}$ and $\mathrm{Zn}-\mathrm{Fe}$ coordination numbers, the effects of both aging time and the desorption step therefore likely represent a transition in dominant $\mathrm{Zn}$ (II) sorption mode from edge-sharing surface-bound inner-sphere complexes at nanoparticle surfaces (primarily associated with ferrihydrite-like surface sites) to corner-sharing surface complexes and substitution of $\mathrm{Zn}$ for Fe cations into the structure of the goethite nanorods (shown schematically in Fig. $\mathbf{6 j}$ ). The increase in the $\mathrm{CN}$ of the Zn-Fe shells between adsorbed and desorbed samples at each discrete aging time also indicates that the adsorbed samples feature a greater proportion of surface-sorbed $\mathrm{Zn}(\mathrm{II})$ species which are relatively weakly bound/under-coordinated and thus more readily desorbed, leaving behind the 
more tightly-bound $\mathrm{Zn}$ (II) which is likely to be structurally incorporated into the nanoparticles and therefore have a greater average number of Fe neighbors surrounding the average $\mathrm{Zn}$ atom.

\subsubsection{Effect of reaction temperature on $\mathrm{Zn}$ speciation}

Fig. 7 plots experimental and fitted Zn K-edge EXAFS spectra and their corresponding Fourier transforms (FT) for samples aged for 96 hours at room temperature $\left(\sim 20^{\circ} \mathrm{C}\right), 50^{\circ} \mathrm{C}$, and $75^{\circ} \mathrm{C}$ and then exposed to the desorption step. As the reaction temperature increases, a shoulder feature in the EXAFS spectra appears between 7-9 $\AA^{-1}$, corresponding most directly to the amplitude of the shortest of the second neighbor FT features.

Quantitative shell-by-shell EXAFS fitting (Table 2) shows that while the Zn-O coordination number remains fairly constant at an average of $4.4 \pm 0.7$, the $\mathrm{Zn}-\mathrm{O}$ interatomic distance again lengthens slightly, from $2.00 \pm 0.01$ to $2.05 \pm 0.01 \AA$. All three Zn-Fe CNs also increase systematically with temperature, with the greatest percentage change (relative to the room temperature sample, indicated as the parameter $\left.\bullet_{\mathrm{CN}-\mathrm{RT}}\right)$ occurring at the shortest interatomic distance at an average of $3.07 \pm 0.02 \AA$ (with $\mathrm{Zn}$-Fe distances themselves remaining constant across all temperatures). These fitting results correlate well with the visual changes observed in the FTs (Fig. 7) and support the incorporation of Zn into the lattice of the goethite nanorods as described in the previous section.

\subsection{Copper sorption}

\subsubsection{Macroscopic adsorption/desorption batch experiments}

At all temperatures and time intervals sampled, the "adsorbed" aliquots indicated $~ 100 \%$ uptake of $\mathrm{Cu}$ (II) (Fig. 8), representing a maximum surface coverage of $0.37 \mu \mathrm{mol} / \mathrm{m}^{2}$ and 
excluding $\mathrm{Cu}$ surface precipitation as a significant concern in the experiments. Similar to the $\mathrm{Zn}$ (II) macroscopic results, the fraction of initial $\mathrm{Cu}$ (II) retained onto the nanoparticles after the desorption step is also directly related to both temperature and aging time (Fig. 8). Over the first 4 hours at $50^{\circ} \mathrm{C}$ and $75^{\circ} \mathrm{C}$ and the first 24 hours at room temperature, $\mathrm{Cu}(\mathrm{II})$ retention increases relatively rapidly, followed by a more gradual increase in retention for the remainder of the experiments' duration. There is no decline in $\mathrm{Cu}$ (II) retention between 24-48 hours as observed in the $\mathrm{Zn}$ (II) macroscopic adsorption/desorption experiments, suggesting a more continuous and permanent process of uptake and retention, with a consistent binding mode, over time. The biphasic retention behavior suggests an initial and rapid uptake step, perhaps as surface sorption complexes, followed by a transition to a more tightly-bound form of $\mathrm{Cu}(\mathrm{II})$ resulting from migration to stronger and/or more ordered surface sites, interparticle pore regions, or substituted locations within the nanoparticle lattice with greater aging times/temperatures.

\subsubsection{EXAFS Analysis}

\subsubsection{Effect of desorption step on $\mathrm{Cu}$ speciation}

Fig. 9 plots experimental and fitted $\mathrm{Cu}$ K-edge EXAFS spectra and Fourier transforms of $\mathrm{Cu}$ adsorption and desorption samples aged for 96 hours at room temperature, $50^{\circ} \mathrm{C}$, and $75^{\circ} \mathrm{C}$. Only minimal qualitative changes can be observed between the pairs of adsorbed/desorbed spectra and corresponding FTs, indicating that, unlike with $\mathrm{Zn}(\mathrm{II}), \mathrm{Cu}(\mathrm{II})$ speciation does not change substantially between the adsorbed and desorbed states. This is consistent with the $\mathrm{Cu}$ (II) macroscopic results, which showed relatively high levels of retained $\mathrm{Cu}(\mathrm{II})$ after 96 hours $\left(98 \%, 93 \%\right.$, and $75 \%$ at $75^{\circ} \mathrm{C}, 50^{\circ} \mathrm{C}$, and room temperature, respectively). The macroscopic and spectroscopic results together show that only a minor fraction of $\mathrm{Cu}(\mathrm{II})$ was removed and that the 
majority of the adsorbed $\mathrm{Cu}(\mathrm{II})$ was retained, presumably in the same (ratio of) sorption mode(s) as when it was initially adsorbed, after the desorption step. In contrast with the $\mathrm{Zn}$ (II) results (where a larger fraction of weakly-bound $\mathrm{Zn}$ (II) was removed during desorption, revealing a transition in dominant sorption mode to more strongly-bound, structurally-incorporated complexes), the $\mathrm{Cu}$ (II) EXAFS spectra at the different temperatures suggest constant binding modes that are not readily desorbed after 96 hours.

Quantitative shell-by-shell fitting results for the $\mathrm{Cu}$ adsorption and desorption samples after 96 hours of aging at the three aging temperatures are shown in Table 3. In order to better compare fitting analyses between the samples, the Debye-Waller factor for the first $\mathrm{Cu}-\mathrm{O}$ shell was initially allowed to float for all fits, then the average value calculated and held constant at $0.004 \AA^{2}$ for the final fitting routine. The resulting fits confirm that both the $\mathrm{Cu}-\mathrm{O}$ and $\mathrm{Cu}-\mathrm{Fe}$ interatomic distances remain essentially constant before and after the desorption step, while the coordination numbers either stay relatively constant $(\mathrm{Cu}-\mathrm{O}$ shells $)$ or increase slightly $(\mathrm{Cu}-\mathrm{Fe}$ shells) after the desorption step at each temperature. Such minimal differences between the adsorbed and desorbed spectral fits indicate either little change in sorption mode or the removal of just a minor fraction of weakly sorbed (e.g. outer-sphere, see Fig. 6a) complexes, and are consistent with the qualitative resemblances between the pairs of adsorption and desorption spectra in Fig. 9. These findings are also comparable to those from Part I of this study showing that $\mathrm{Cu}$ (II) speciation to $\mathrm{pH}$ - and ionic strength-aggregated nanoparticles is essentially identical after both the adsorption and desorption stages of the experiment.

\subsubsection{Effect of reaction temperature on $\mathrm{Cu}$ speciation}


Although the speciation of $\mathrm{Cu}(\mathrm{II})$ does not differ significantly between the adsorption and desorption spectra at a given temperature, the reaction temperature at which sorption occurs does significantly affect speciation. The desorption spectra in Fig. 9 show the progressive growth of a shoulder feature at $\sim 7.5 \AA^{-1}$ with increasing temperature which corresponds to the presence of a distant second-neighbor feature in the FTs, indicating a transition in the $\mathrm{Cu}(\mathrm{II})$ binding environment with temperature.

The quantitative fitting results of the desorption spectra in Table 3 confirm this transition. The $\mathrm{Cu}-\mathrm{O}$ shell fit results, with coordination numbers averaging $3.3 \pm 0.6$ at a radial distance of $1.96 \pm 0.01 \AA$, are consistent with the presence of an octahedrally-coordinated $\mathrm{Cu}$ (II) sorption complex which has undergone Jahn-Teller distortion such that the four equatorial oxygen atoms dominate the scattering of the first shell, as has been observed by our past work (GILBERT et al., 2009) and that of others (BOCHATAY et al., 1997; GILBERT et al., 2009; PARKMAN et al., 1999).

Fits of the second-neighbor FT features were attempted with both $\mathrm{Cu}-\mathrm{Fe}$ and $\mathrm{Cu}-\mathrm{Cu}$ scattering paths, but the resulting similarities in the fits confirm past studies which found that the phase amplitude fitting cannot readily differentiate between $\mathrm{Cu}-\mathrm{Fe}$ and $\mathrm{Cu}-\mathrm{Cu}$ shells (PEACOCK and SHERMAN, 2004); accordingly, fits of these features could be interpreted as the result of either $\mathrm{Cu}-\mathrm{Fe}$ or $\mathrm{Cu}-\mathrm{Cu}$ scattering interactions. The shortest second-neighbor feature, fit with a $\mathrm{Cu}-\mathrm{Fe} / \mathrm{Cu}$ shell at an average distance of $3.04 \pm 0.02 \AA$, is most consistent with $\mathrm{Cu}$ ions forming inner-sphere sorption complexes either as dimers in binuclear corner-sharing configurations (Fig. 6f) or as monomers in mononuclear bidentate edge-sharing configurations (Fig. 6c) with the $\mathrm{Fe}(\mathrm{O}, \mathrm{OH})_{6}$ octahedra that comprise the substrate. The coordination number of this feature declines with increasing temperature (as evidenced by the percentage change in coordination 
number relative to the room temperature sample, represented in Table 3 as $\bullet_{\mathrm{CN}-\mathrm{RT}}$ ), indicating that this sorption mode is more prevalent at lower temperatures and becomes less common at higher temperatures.

After inducing desorption in the sample aged at room temperature for 96 hours, the most distant second-neighbor shell, fit with $1.9 \pm 0.6$ atoms at $3.27 \pm 0.02 \AA$, correlates with mononuclear bidentate inner-sphere sorption complexes in corner-sharing configurations with the $\mathrm{Fe}(\mathrm{O}, \mathrm{OH})_{6}$ octahedra of goethite, as observed in other EXAFS studies of $\mathrm{Cu}(\mathrm{II})$ on iron hydroxide substrates (GILBERT et al., 2009; PEACOCK and SHERMAN, 2004). However, at $75^{\circ} \mathrm{C}$ the most distant second-neighbor shell is best fit with $1.5 \pm 0.7 \mathrm{Cu} / \mathrm{Fe}$ atoms at $3.83 \pm 0.04 \AA$, indicating a fundamentally different binding environment that has not to our knowledge been previously reported in the literature and is not consistent with a previous EXAFS study of $\mathrm{Cu}$ substitution into goethite (MANCEAU et al., 2000), which identifies $\mathrm{Cu}-\mathrm{Fe}$ interactions at 3.00, 3.23, and $3.48 \AA$. The unique fitting results of the $75^{\circ} \mathrm{C}$ spectrum can, however, be satisfied by the presence of a copper dimer that is located at the interface between two nanoparticles, such that it is bound by Fe octahedra on opposite sides of the dimer complex (Fig. 6i); the trapping of an initially surface-bound copper dimer at a particle-particle interface during nanoparticle aggregation could produce such a configuration. This fitting result may therefore indicate the presence of copper dimers located within a nanoporous aggregate, representing a unique mechanism of structural incorporation of metals that can be detected at elevated temperatures and aging times. Based on the TEM data from this study and our previous XRD work (KIM et al., 2008), $\mathrm{Cu}(\mathrm{II})$ sorption of the types described here may inhibit oriented nanoparticle aggregation through surface sorption and passivation. 
Notably, the EXAFS spectrum of the $50^{\circ} \mathrm{C}$ desorbed sample can be best fit by including both of the $\mathrm{Cu}-\mathrm{Fe} / \mathrm{Cu}-\mathrm{Cu}$ second-neighbor shells identified at room temperature and $75^{\circ} \mathrm{C}$. Thus, the $50^{\circ} \mathrm{C}$ sample may represent a transitional state between the lower and higher temperatures wherein all potential sorbed species described earlier are present in detectable proportions. Accordingly, with increasing aging temperature, the dominant sorption mode of copper ions may transition from monomers and dimers associated with the nanoparticle surface as inner-sphere sorption complexes to more structurally-incorporated dimers securely held within nanoporous regions between aggregated nanoparticles. The macroscopic retention data supports this explanation as well, with the structurally-incorporated species more strongly retained and less likely to be desorbed back into solution than the surface-sorbed species that are more prevalent at lower aging temperatures.

\subsubsection{Effects of reaction time on $\mathrm{Cu}$ speciation at room temperature}

Fig. 10 plots experimental and fitted $\mathrm{Cu}$ K-edge EXAFS spectra and Fourier transforms for desorbed samples conducted at room temperature at selected times. The EXAFS spectra reveal only subtle changes as aging time increases, with an apparent gradual increase in oscillation amplitude but no prominent shoulder in the data as observed in the samples aged at $75^{\circ} \mathrm{C}$. The Fourier transform plot shows similarly subtle increases in amplitudes of the first- and second-neighbor features with time.

The quantitative fitting results of the room temperature-aged samples presented in Table 4 reveal relatively constant $\mathrm{Cu}-\mathrm{O}$ distances (averaging $1.95 \pm 0.01 \AA$ ) and $\mathrm{Cu}-\mathrm{Fe} / \mathrm{Cu}$ distances (averaging $3.05 \pm 0.04 \AA$ and $3.26 \pm 0.04 \AA$ ) throughout the duration of the experimental trial. These interatomic distances determined by the EXAFS fits agree with the aforementioned 
structural models of $\mathrm{Cu}(\mathrm{II})$ ions binding as binuclear (dimer) and mononuclear bidentate cornerand edge-sharing sorption complexes (Figs. 6c, 6e, 6f). Notably, both the $\mathrm{Cu}-\mathrm{O}$ and $\mathrm{Cu}-\mathrm{Fe} / \mathrm{Cu}$ coordination numbers change measurably over time as demonstrated by the ${ }_{\mathrm{CN}-\mathrm{Ohr}}$ parameter $(\%$ change in coordination number relative to the 0 -hour sample). This parameter shows that for the first 12 hours of aging the $\mathrm{Cu}-\mathrm{O}$ coordination number increases while the $\mathrm{Cu}-\mathrm{Fe} / \mathrm{Cu}$ coordination numbers remain statistically equivalent or slightly decline, after which time all coordination numbers increase significantly and remain constantly elevated from 24-96 hours (Table 4). The EXAFS fitting results correlate well with the macroscopic data (Fig. 8), where at room temperature the extent of $\mathrm{Cu}(\mathrm{II})$ retention progressively increases and then reaches a plateau at 24 hours, which continues for the remainder of the experiment's timeframe.

The observed changes in coordination number can be explained by a shift in the proportion of different sorption modes present over time. Specifically, a significant amount (42$57 \%$ ) of the $\mathrm{Cu}(\mathrm{II})$ that sorbs to the nanoparticles within the first 12 hours is bound more weakly (e.g. as outer-sphere complexes and inner-sphere complexes attached to structurally disordered/less stable sites) and is readily removed from nanoparticle surfaces by a lowering of $\mathrm{pH}$, leaving behind retained $\mathrm{Cu}(\mathrm{II})$ species that are sufficiently strongly bound to resist this desorption step. The corresponding lower coordination numbers associated with the EXAFS fits of samples collected from 0-12 hours suggest that some of the more weakly-bound species remain associated with the sample after desorption. However, after 24 hours a greater fraction of $\mathrm{Cu}(\mathrm{II})$ is affiliated with the nanoparticles in more strongly-binding fashion(s) (only $26 \%$ desorbs), such as in inner-sphere bidentate corner-sharing mode, as $\mathrm{Cu}(\mathrm{II})$ dimers, and/or through ion substitution for Fe in the nanoparticle lattice. The trend in the macroscopic data at 
room temperature suggests that these configurations dominate after as few as 24 hours of uptake at room temperature.

\section{CONCLUSIONS}

Pairing macroscopic metal adsorption/desorption experiments with corresponding spectroscopic analyses of samples provides direct insight into changes in the speciation of metal ions associated with nanoparticle aggregates. Specifically, the mechanism of nanoparticle aggregation impacts both the extent and mode of metal uptake/retention in significant ways, as evidenced by this study's investigation of temperature-based aging of nanoparticles, a companion study (Part I of this two-part series) on the effects of aggregation by increased $\mathrm{pH}$ and ionic strength (DALE et al., 2014 (submitted)), and an earlier investigation that included aggregation by freezing and drying nanoparticle suspensions at different temperatures (GILBERT et al., 2009).

The current study's focus on aging as a function of temperature and time demonstrates that both variables are generally correlated with increased retention of $\mathrm{Cu}$ (II) and $\mathrm{Zn}$ (II) to iron oxyhydroxide nanoparticle aggregates. A decline in Zn(II) retention observed between 24-48 hours at all temperatures may be attributed to the previously-documented onset of goethite nanorod formation via oriented nanoparticle aggregation (GUYODO et al., 2003; PENN et al., 2006; WAYCHUNAS et al., 2005), which could induce a fraction of the sorbed Zn(II) to be released from the initial ellipsoidal nanoparticles and subsequently re-adsorbed to the more structurally regular, faceted nanorods. In contrast, $\mathrm{Cu}$ (II) displayed a more rapid increase and stabilization in retention with time across all temperatures; this behavior, consistent with TEM 
studies and prior XRD studies (KIM et al., 2008), suggests that $\mathrm{Cu}(\mathrm{II})$ sorption to nanoparticle surfaces inhibits the oriented aggregation that leads to nanorod formation, thus allowing the nanoparticles to maintain their initial ellipsoidal morphology during aggregation. The sorption of metals and other ligands may similarly explain the persistence of nanoscale, poorly-crystalline aggregates in natural systems.

Spectroscopic analysis indicates an overall trend with increasing time, further enhanced with increasing temperature, of sorbed metal species transitioning from surface-bound metal ions, which can be more easily desorbed and returned to solution, to more strongly-bound surface and structurally-incorporated metal ions which are affiliated intimately with the nanoparticle aggregates through either ion substitution into the nanoparticle lattice or binding within nanoparticle aggregate pore spaces / interfaces. When both strong and weak sorption configurations are present at a given aging time, as with $\mathrm{Zn}(\mathrm{II})$, comparison of the adsorbed and desorbed samples' EXAFS spectra reveal differences that suggest the removal of the weaklyheld species and retention of the strongly-held species. With $\mathrm{Cu}(\mathrm{II})$, a more uniform mode of sorption appears to exist at each discrete time/temperature condition, yielding adsorbed and desorbed EXAFS spectra that are very similar to one another. However, a systematic change in sorption speciation can still be observed with time and temperature from $\mathrm{Cu}(\mathrm{II})$ sorbed to the nanoparticle surface to the aforementioned structurally-incorporated forms of $\mathrm{Cu}(\mathrm{II})$.

The differences between $\mathrm{Zn}$ (II) and $\mathrm{Cu}(\mathrm{II})$ sorption behavior show that the identity of the metal sorbate is a determining factor in both the mode of adsorption and degree of retention. Furthermore, in both cases multiple modes of metal uptake to the nanoparticle aggregates can be discerned as a function of temperature and time, representing a range of binding configurations and thus of binding strengths as shown schematically in Fig. 6. Characterizing such transitions 
in speciation and the relationships between aggregation state and sorption mode can inform our understanding of the long-term retention of metals and the potential for metals to desorb and remobilize under changing aqueous geochemical conditions. This is relevant to a number of systems including mining environments, where acidic mine waters are periodically introduced to nearby drainage systems during storm events, and coastal regions, where salinity progressively increases as suspended sediments are transported towards the ocean and sorbed metals can remobilize from particulate surfaces.

An overview of several aggregation mechanisms explored in this and our prior studies enables us to summarize a number of key findings, shown graphically in Fig. 11. The degree of nanoparticle aggregation generally increases as follows: ionic strength $\sim \mathrm{pH}<$ aging $<$ freezing $<$ drying. Accordingly, the extent of interstitial water and pore space between aggregated particles decreases along this series, resulting in greater compaction of the aggregates. A parallel loss of reactive surface area is also expected with an increasing degree of aggregation, although accurately measuring the surface areas of nanoparticle aggregate suspensions remains a challenge due to artifacts associated with the drying required of most surface area methods.

The retention of sorbed metals increases with aggregation state, due to physical constraints to desorption caused by aggregation (e.g. sorption within interparticle nanoporous regions), incorporation into the solid substrate, and/or increasing proportions of higher-strength binding sites. Accordingly, the dominant mode(s) of sorption evolves from outer-sphere complexes to progressively more strongly-bound inner-sphere surface complexes to structurally incorporated ions and lattice substitution. These findings, considered together, establish a broad framework to describe the process of metal ion adsorption to nanoparticle aggregates by 
including the processes of metal desorption and metal retention and accounting for the range of sorption complexes that are likely to occur onto, between, and within nanoparticle surfaces.

\section{Acknowledgements}

This work was funded by the National Science Foundation, Division of Earth Sciences, Grant \#061821711, Cottrell College Science Award \#6940/6912 from the Research Corporation, and a Henry Dreyfus Teacher-Scholar Award. Portions of this research were carried out at the Stanford Synchrotron Radiation Lightsource, a national user facility operated by Stanford University on behalf of the U.S. Department of Energy, Office of Basic Energy Sciences. The assistance of SSRL staff scientists Joe Rogers, Sam Webb, and John Bargar in EXAFS data collection was greatly appreciated. The authors thank Dr. Jian-Guo Zheng at the University of California, Irvine for lending his expertise in collecting TEM data. Thanks also to members of the Chapman University Environmental Geochemistry Lab for their earlier studies on metal uptake and iron oxyhydroxide nanoparticle aggregation.

\section{Citations}

Alvarez, M., Rueda, E. H., and Sileo, E. E., 2007. Simultaneous incorporation of Mn and Al in the goethite structure. Geochimica et Cosmochimica Acta 71, 1009-1020.

Alvarez, M., Sileo, E. E., and Rueda, E. H., 2005. Effect of Mn(II) incorporation on the transformation of ferrihydrite to goethite. Chemical Geology 216, 89-97.

Baalousha, M., 2009. Aggregation and disaggregation of iron oxide nanoparticles: Influence of particle concentration, $\mathrm{pH}$ and natural organic matter. Science of The Total Environment 407, 2093-2101.

Banfield, J. F. and Navrotsky, A., 2001. Nanoparticles and the Environment. Mineralogical Society of America.

Banfield, J. F., Welch, S. A., Zhang, H., Ebert, T. T., and Penn, R. L., 2000. Aggregation-Based Crystal Growth and Microstructure Development in Natural Iron Oxyhydroxide Biomineralization Products. Science 289, 751-754.

Benjamin, M. M. and Leckie, J. O., 1981. Multiple-site adsorption of $\mathrm{Cd}, \mathrm{Cu}, \mathrm{Zn}$, and $\mathrm{Pb}$ on amorphous iron oxyhydroxide. Journal of Colloid \& Interface Science 79, 209-221. 
Bochatay, L., Persson, P., Lovgren, L., and Brown, G. E., 1997. XAFS study of Cu(II) at the water-goethite (alpha-FeOOH) interface. Journal De Physique IV 7, 819-820.

Carabante, I., Grahn, M., Holmgren, A., Kumpiene, J., and Hedlund, J., 2009. Adsorption of As (V) on iron oxide nanoparticle films studied by in situ ATR-FTIR spectroscopy. Colloids and Surfaces A: Physicochemical and Engineering Aspects 346, 106-113.

CrystalMaker, http://www.crystalmaker.com/.

Cwiertny, D. M., Handler, R. M., Schaefer, M. V., Grassian, V. H., and Scherer, M. M., 2008. Interpreting nanoscale size-effects in aggregated Fe-oxide suspensions: Reaction of Fe(II) with goethite. Geochimica et Cosmochimica Acta 72, 1365-1380.

Dale, J. G., Stegemeier, J. P., and Kim, C. S., 2014 (submitted). Aggregation of nanoscale iron oxyhydroxides and corresponding effects on metal uptake, retention, and speciation: I. Ionic strength and $\mathrm{pH}$. Geochimica et Cosmochimica Acta.

Davis, J. A., Fuller, C. C., and Cook, A. D., 1987. A model for trace metal sorption processes at the calcite surface: Adsorption of $\mathrm{Cd} 2+$ and subsequent solid solution formation. Geochimica et Cosmochimica Acta 51, 1477-1490.

Erbs, J. J., Berquó, T. S., Reinsch, B. C., Lowry, G. V., Banerjee, S. K., and Penn, R. L., 2010. Reductive dissolution of arsenic-bearing ferrihydrite. Geochimica et Cosmochimica Acta 74, 3382-3395.

Fukushi, K. and Sverjensky, D. A., 2007. A predictive model (ETLM) for arsenate adsorption and surface speciation on oxides consistent with spectroscopic and theoretical molecular evidence. Geochimica et Cosmochimica Acta 71, 3717-3745.

Gilbert, B., 2007. Stable cluster formation in aqueous suspensions of iron oxyhydroxide nanoparticles. Journal of Colloid and Interface Science 313, 152-159.

Gilbert, B., Huang, F., Zhang, H. Z., Waychunas, G. A., and Banfield, J. F., 2004. Nanoparticles: Strained and stiff. Science 305, 651-654.

Gilbert, B., Ono, R. K., Ching, K. A., and Kim, C. S., 2009. The effects of nanoparticle aggregation processes on aggregate structure and metal uptake. Journal of Colloid and Interface Science 339, 285-295.

Grossl, P. R. and Sparks, D. L., 1995. Evaluation of contaminant ion adsorption/desorption on goethite using pressure jump relaxation kinetics. Geoderma 67, 87-101.

Guyodo, Y., Mostrom, A., Penn, R. L., and Banerjee, S. K., 2003. From Nanodots to Nanorods: Oriented aggregation and magnetic evolution of nanocrystalline goethite. Geophys. Res. Lett 30, 1512.

Hiemstra, T., Antelo, J., Rahnemaie, R., and van Riemsdijk, W. H., 2010. Nanoparticles in natural systems I: The effective reactive surface area of the natural oxide fraction in field samples. Geochimica et Cosmochimica Acta 74, 41-58.

Hochella, M. F., 2002. Nanoscience and technology the next revolution in the Earth sciences. Earth and Planetary Science Letters 203, 593-605.

Jeon, B. H., Dempsey, B. A., Burgos, W. D., and Royer, R. A., 2003. Sorption kinetics of Fe(II), $\mathrm{Zn}(\mathrm{II}), \mathrm{Co}(\mathrm{II}), \mathrm{Ni}(\mathrm{II}), \mathrm{Cd}(\mathrm{II})$, and Fe(II)/Me(II) onto hematite. Water Research 37, 41354142.

Juillot, F., Maréchal, C., Ponthieu, M., Cacaly, S., Morin, G., Benedetti, M., Hazemann, J. L., Proux, O., and Guyot, F., 2008. Zn isotopic fractionation caused by sorption on goethite and 2-Lines ferrihydrite. Geochimica et Cosmochimica Acta 72, 4886-4900.

Kersting, A. B., Efurd, D. W., Finnegan, D. L., Rokop, D. J., Smith, D. K., and Thompson, J. L., 1999. Migration of plutonium in ground water at the Nevada Test Site. Nature 397, 5659. 
Kim, C. S., Lentini, C. J., and Waychunas, G. A., 2008. Associations between iron oxyhydroxide nanoparticle growth and metal adsorption/structural incorporation. In: Barnett, M. O. and Kent, D. Eds.), Developments in Earth and Environmental Sciences. Elsevier.

Kim, C. S., Lentini, C. J., Waychunas, G. A., and Mark, O. B. a. D. B. K., 2007. Chapter 6 Associations between Iron Oxyhydroxide Nanoparticle Growth and Metal Adsorption/Structural Incorporation, Developments in Earth and Environmental Sciences. Elsevier.

Kim, C. S., Rytuba, J. J., and Brown, G. E., Jr., 2004. EXAFS study of mercury(II) sorption to Fe- and Al-(hydr)oxides: I. Effects of pH. Journal of Colloid and Interface Science 271, $1-15$.

Lin, S. H., Kao, H. C., Cheng, C. H., and Juang, R. S., 2004. An EXFAS study of the structures of copper and phosphate sorbed onto goethite. Colloids and Surfaces a-Physicochemical and Engineering Aspects 234, 71-75.

Liu, J., Aruguete, D. M., Murayama, M., and Hochella, M. F., Jr., 2009. Influence of Size and Aggregation on the Reactivity of an Environmentally and Industrially Relevant Nanomaterial (PbS). Environmental Science \& Technology 43, 8178-8183.

Madden, A. S., Hochella, M. F., and Luxton, T. P., 2006. Insights for size-dependent reactivity of hematite nanomineral surfaces through $\mathrm{Cu} 2+$ sorption. Geochimica et Cosmochimica Acta 70, 4095-4104.

Manceau, A., 1995. The mechanism of anion adsorption on iron-oxides - evidence for the bonding of arsenate tetrahedra on free $\mathrm{Fe}(\mathrm{O}, \mathrm{Oh})(6)$ edges. Geochimica et Cosmochimica Acta 59, 3647-3653.

Manceau, A., Schlegel, M. L., Musso, M., Sole, V. A., Gauthier, C., Petit, P. E., and Trolard, F., 2000. Crystal chemistry of trace elements in natural and synthetic goethite. Geochimica Et Cosmochimica Acta 64, 3643-3661.

Martinez, C. E. and McBride, M. B., 1998. Coprecipitates of $\mathrm{Cd}, \mathrm{Cu}, \mathrm{Pb}$ and $\mathrm{Zn}$ in iron oxides: Solid phase transformation and metal solubility after aging and thermal treatment. Clays and Clay Minerals 46, 537-545.

Mustafa, G., Kookana, R. S., and Singh, B., 2006. Desorption of cadmium from goethite: Effects of $\mathrm{pH}$, temperature and aging. Chemosphere 64, 856-865.

Nachtegaal, M. and Sparks, D. L., 2004. Effect of iron oxide coatings on zinc sorption mechanisms at the clay-mineral/water interface. Journal of Colloid and Interface Science 276, 13-23.

Novikov, A. P., Kalmykov, S. N., Utsunomiya, S., Ewing, R. C., Horreard, F., Merkulov, A., Clark, S. B., Tkachev, V. V., and Myasoedov, B. F., 2006. Colloid transport of plutonium in the far-field of the Mayak Production Association, Russia. Science 314, 638-641.

Ostergren, J. D., Trainor, T. P., Bargar, J. R., Brown, G. E., Jr., and Parks, G. A., 2000. Inorganic ligand effects on $\mathrm{Pb}(\mathrm{II})$ sorption to goethite $(\mathrm{a}-\mathrm{FeOOH})$ : I. Carbonate. Journal of Colloid and Interface Science 225, 466-482.

Parkman, R. H., Charnock, J. M., Bryan, N. D., Livens, F. R., and Vaughan, D. J., 1999. Reactions of copper and cadmium ions in aqueous solution with goethite, lepidocrocite, mackinawite, and pyrite. American Mineralogist 84, 407-419.

Peacock, C. L. and Sherman, D. M., 2004. Copper(II) sorption onto goethite, hematite and lepidocrocite: A surface complexation model based on ab initio molecular geometries and EXAFS spectroscopy. Geochimica et Cosmochimica Acta 68, 2623-2637.

Penn, R. L., Erbs, J. J., and Gulliver, D. M., 2006. Controlled growth of alpha-FeOOH nanorods by exploiting-oriented aggregation. Journal of Crystal Growth 293, 1-4. 
Penn, R. L., Tanaka, K., and Erbs, J., 2007. Size dependent kinetics of oriented aggregation. Journal of Crystal Growth 309, 97-102.

Penn, R. L., Zhu, C., Xu, H., and Veblen, D. R., 2001. Iron oxide coatings on sand grains from the Atlantic coastal plain: High-resolution transmission electron microscopy characterization. Geology 29, 843-846.

Plathe, K. L., von der Kammer, F., Hassellov, M., Moore, J., Murayama, M., Hofmann, T., and Hochella, M. F., Jr., 2010. Using FIFFF and aTEM to determine trace metal-nanoparticle associations in riverbed sediment. Environmental Chemistry 7, 82-93.

Plathe, K. L., von der Kammer, F., Hassellov, M., Moore, J. N., Murayama, M., Hofmann, T., and Hochella, M. F., Jr., 2013. The role of nanominerals and mineral nanoparticles in the transport of toxic trace metals: Field-flow fractionation and analytical TEM analyses after nanoparticle isolation and density separation. Geochimica Et Cosmochimica Acta 102, 213-225.

Rehr, J. J. and Albers, R. C., 2000. Theoretical approaches to x-ray absorption fine structure. Reviews of Modern Physics 72, 621-654.

Roberts, D. R., Ford, R. G., and Sparks, D. L., 2003. Kinetics and mechanisms of Zn complexation on metal oxides using EXAFS spectroscopy. Journal of Colloid and Interface Science 263, 364-376.

Sahai, N., 2007. Role of Fe(II) and phosphate in arsenic uptake by coprecipitation. Geochemica et Cosmochimica Acta 71, 3193-3210.

Srivastava, A. a. P. C. S., 1990. Adsorption-Desorption Behavior of Zinc(II) at Iron(III) Hydroxide-Aqueous Solution Interface as Influenced by $\mathrm{pH}$ and Temperature. Environmental Pollution 68, 171-180.

Trainor, T. P., Brown, G. E., Jr., and Parks, G. A., 2000. Adsorption and precipitation of aqueous $\mathrm{Zn}(\mathrm{II})$ on alumina powders. Journal of Colloid and Interface Science 231, 359-372.

Trivedi, P. and Axe, L., 2000. Modeling Cd and Zn sorption to hydrous metal oxides. Environmental Science \& Technology 34, 2215-2223.

Trivedi, P. and Axe, L., 2001a. Ni and Zn sorption to amorphous versus crystalline iron oxides: Macroscopic studies. Journal of Colloid and Interface Science 244, 221-229.

Trivedi, P. and Axe, L., 2001b. Predicting divalent metal sorption to hydrous Al, Fe, and Mn oxides. Environmental Science \& Technology 35, 1779-1784.

Trivedi, P., Axe, L., and Tyson, T. A., 2001. An analysis of zinc sorption to amorphous versus crystalline iron oxides using XAS. Journal of Colloid and Interface Science 244, 230238.

van der Zee, C. and Roberts, D. R., 2003. Nanogoethite is the dominant reactive oxyhydroxide phase in lake and marine sediments. Geology 31, 993-996.

Venema, P., Hiemstra, T., and van Riemsdijk, W. H., 1996. Multisite adsorption of cadmium on goethite. Journal of Colloid and Interface Science 183, 515-527.

Vilks, P., Frost, L. H., and Bachinski, D. B., 1997. Field-scale colloid migration experiments in a granite fracture. Journal of Contaminant Hydrology 26, 203-214.

Villalobos, M., Trotz, M. A., and Leckie, J. O., 2003. Variability in goethite surface site density: evidence from proton and carbonate sorption. Journal of Colloid \& Interface Science 268, 273-287.

Violante, A., Del Gaudio, S., Pigna, M., Ricciardella, M., and Banerjee, D., 2007.

Coprecipitation of arsenate with metal oxides. 2. Nature, mineralogy, and reactivity of iron(III) precipitates. Environmental Science \& Technology 41, 8275-8280. 
Waychunas, G. A. and Brown, G. E., Jr., 1994. Fluorescence yield XANES and EXAFS experiments: application to highly dilute and surface samples. Advances in X-Ray Analysis 37, 607-617.

Waychunas, G. A., Fuller, C. C., and Davis, J. A., 2002. Surface complexation and precipitate geometry for aqueous $\mathrm{Zn}$ (II) sorption on ferrihydrite I: X-ray absorption extended fine structure spectroscopy analysis. Geochimica Et Cosmochimica Acta 66, 1119-1137.

Waychunas, G. A., Kim, C. S., and Banfield, J. F., 2005. Nanoparticulate oxide minerals in soils and sediments: unique properties and contaminant scavenging mechanisms. Journal of Nanoparticle Research 7, 409-433.

Webb, S. M., 2005. SIXpack: a graphical user interface for XAS analysis using IFEFFIT. Phys. Scr. T115, 1011-1014.

Yin, Y. J., Allen, H. E., Huang, C. P., Sparks, D. L., and Sanders, P. F., 1997. Kinetics of mercury(II) adsorption and desorption on soil. Environmental Science \& Technology 31, 496-503.

Yuwono, V. M., Burrows, N. D., Soltis, J. A., and Penn, R. L., 2010. Oriented aggregation: formation and transformation of mesocrystal intermediates revealed. Journal of the American Chemical Society 132, 2163-2165.

\section{Table Captions}

Table 1. Zn K-edge EXAFS fitting results for adsorbed and desorbed samples aged at $75^{\circ} \mathrm{C}$ for 4, 24, and 96 hours.

Table 2. Zn K-edge EXAFS fitting results for desorbed samples aged for 96 hours at room temperature $\left(\sim 20^{\circ} \mathrm{C}\right), 50^{\circ} \mathrm{C}$, and $75^{\circ} \mathrm{C}$.

Table 3. $\mathrm{Cu}$ K-edge EXAFS fitting results for adsorbed and desorbed samples aged for 96 hours at $75^{\circ} \mathrm{C}$ and room temperature.

Table 4. $\mathrm{Cu}$ K-edge EXAFS fitting results for desorbed samples aged from 0-96 hours at room temperature. 
Table 1.

\begin{tabular}{|c|c|c|c|c|c|c|c|c|c|c|c|c|c|c|c|}
\hline \multirow[t]{2}{*}{ Sample } & \multicolumn{4}{|c|}{ Zn-O } & \multicolumn{3}{|c|}{${\mathrm{Zn}-F e^{*}}$} & \multicolumn{3}{|c|}{$\mathbf{Z n}-\mathrm{Fe}^{*}$} & \multicolumn{3}{|c|}{$\mathbf{Z n}-\mathbf{F e}^{*}$} & \multirow{2}{*}{$\begin{array}{c}\mathbf{E}_{0} \\
\text { shift } \\
(\mathrm{eV})\end{array}$} & \multirow{2}{*}{$\begin{array}{c}\text { R- } \\
\text { factor }\end{array}$} \\
\hline & $\mathrm{CN}$ & $\Delta_{\mathrm{CN}-\mathrm{AD}}$ & $\mathrm{R}(\AA)$ & $\sigma^{2}\left(\AA^{2}\right)$ & $\mathrm{CN}$ & $\Delta_{\mathrm{CN}-\mathrm{AD}}$ & $\mathrm{R}(\AA)$ & $\mathrm{CN}$ & $\Delta_{\mathrm{CN}-}$ & $\mathrm{R}(\AA)$ & $\mathrm{CN}$ & $\Delta_{\mathrm{CN}-}$ & $\mathrm{R}(\AA)$ & & \\
\hline $75 \mathrm{C} 96 \mathrm{~h} \mathrm{~A}$ & $4.1(7)$ & & $2.00(1)$ & $.009(2)$ & $0.8(4)$ & & $3.04(3)$ & $1.8(8)$ & & $3.33(4)$ & $2.2(8)$ & & $3.49(3)$ & -14.6 & 0.0307 \\
\hline 75C 96h D & $4.5(7)$ & $10 \%$ & $2.05(1)$ & $.010(1)$ & $2.1(5)$ & $163 \%$ & $3.05(1)$ & $2.9(9)$ & $61 \%$ & $3.30(2)$ & $2.6(7)$ & $18 \%$ & $3.49(2)$ & -12.1 & 0.0250 \\
\hline $75 \mathrm{C} 24 \mathrm{~h} \mathrm{~A}$ & $3.8(6)$ & & $1.99(1)$ & $.008(2)$ & $0.3(4)$ & & $3.04(7)$ & $1.8(7)$ & & $3.35(5)$ & $2.1(8)$ & & $3.50(4)$ & -14.6 & 0.0309 \\
\hline $75 \mathrm{C} 24 \mathrm{~h} \mathrm{D}$ & $4.5(9)$ & $18 \%$ & $2.03(2)$ & $.011(2)$ & $1.3(5)$ & $333 \%$ & $3.05(2)$ & $2.0(1.0)$ & $11 \%$ & $3.31(3)$ & $2.4(8)$ & $14 \%$ & $3.50(3)$ & -12.2 & 0.0434 \\
\hline $75 \mathrm{C} 4 \mathrm{~h} \mathrm{~A}^{* *}$ & $4.9(8)$ & & $1.95(1)$ & $.007(2)$ & - & & - & $1.3(7)$ & & $3.25(4)$ & $2.2(7)$ & & $3.43(3)$ & -18.2 & 0.0290 \\
\hline $75 \mathrm{C} 4 \mathrm{~h} D$ & $4.7(1.1)$ & $-4 \%$ & $1.99(2)$ & $.010(3)$ & $0.6(7)$ & N/A & $3.04(6)$ & $1.6(1.3)$ & $23 \%$ & $3.31(6)$ & $2.2(1.1)$ & $0 \%$ & $3.49(4)$ & -14.9 & 0.0624 \\
\hline
\end{tabular}

Note: Standard deviations at a 95\% confidence level $( \pm 2)$ are listed in parentheses.

$\mathrm{CN}$ : coordination number; ${ }_{\mathrm{CN}-\mathrm{AD}}$ : change in coordination number when comparing adsorbed to desorbed spectra; R: interatomic distance; and ${ }^{2}$ : Debye-Waller factor. $\mathrm{S}_{0}=0.9$.

"Value of ${ }^{2}$ fixed at $0.0081 \AA^{2}$ in least-squares refinement.

***averaged over shorter k-range of $2.75-10.40 \AA^{-1}$ due to lower spectral quality. 
Table 2.

\begin{tabular}{|c|c|c|c|c|c|c|c|c|c|c|c|c|c|c|c|}
\hline \multirow{2}{*}{ Sample } & \multicolumn{4}{|c|}{ Zn-O } & \multicolumn{3}{|c|}{$\mathrm{Zn}-\mathrm{Fe}^{*}$} & \multicolumn{3}{|c|}{$\mathrm{Zn}-\mathrm{Fe}^{*}$} & \multicolumn{3}{|c|}{$\mathrm{Zn}-\mathrm{Fe}^{*}$} & \multirow{2}{*}{$\begin{array}{c}E_{0} \\
\text { shift } \\
(e V)\end{array}$} & \multirow[t]{2}{*}{ R-factor } \\
\hline & $\mathrm{CN}$ & $\bullet_{\mathrm{CN}-\mathrm{RT}}$ & $\mathrm{R}(\AA)$ & ${ }^{2}\left(\AA^{2}\right)$ & $\mathrm{CN}$ & $\bullet_{\mathrm{CN}-\mathrm{RT}}$ & $\mathrm{R}(\AA)$ & $\mathrm{CN}$ & $\bullet_{\mathrm{CN}-}$ & $\mathrm{R}(\AA)$ & $\mathrm{CN}$ & $\bullet_{\mathrm{CN}-}$ & $\mathrm{R}(\AA)$ & & \\
\hline $75 \mathrm{C} 96 \mathrm{~h} \mathrm{D}$ & $4.5(7)$ & $-4 \%$ & $2.05(1)$ & $.010(1)$ & $2.1(5)$ & $320 \%$ & $3.05(1)$ & $2.9(9)$ & $81 \%$ & $3.30(2)$ & $2.6(7)$ & $53 \%$ & $3.49(2)$ & -12.1 & 0.0250 \\
\hline $50 \mathrm{C} 96 \mathrm{~h} \mathrm{D}$ & $4.3(1.0)$ & $-9 \%$ & $2.02(2)$ & $.010(3)$ & $1.3(7)$ & $160 \%$ & $3.06(2)$ & $2.4(1.3)$ & $50 \%$ & $3.30(3)$ & $2.5(1.0)$ & $47 \%$ & $3.49(3)$ & -13.5 & 0.0574 \\
\hline RT 96h D & $4.7(7)$ & - & $2.00(1)$ & $.011(2)$ & $0.5(5)$ & - & $3.11(4)$ & $1.6(9)$ & - & $3.33(4)$ & $1.7(7)$ & - & $3.51(3)$ & -13.7 & 0.0231 \\
\hline
\end{tabular}

Note: Standard deviations at a 95\% confidence level ( \pm 20 ) are listed in parentheses.

$\mathrm{CN}$ : coordination number, $\bullet_{\mathrm{CN}-\mathrm{RT}}$ : change in coordination number relative to the room temperature sample, $\mathrm{R}$ : interatomic distance, and

2 : Debye-Waller factor. $\mathrm{S}_{0}=0.9$.

"Value of ó $^{2}$ fixed at $0.0081 \AA^{2}$ in least-squares refinement. 
Table 3.

\begin{tabular}{|c|c|c|c|c|c|c|c|c|c|c|c|c|c|c|c|c|}
\hline \multirow[t]{2}{*}{ Sample } & \multicolumn{5}{|c|}{$\mathrm{Cu}-\mathrm{O}$} & \multicolumn{4}{|c|}{$\mathrm{Cu}-\mathrm{Fe} / \mathrm{Cu}^{*}$} & \multicolumn{4}{|c|}{$\mathrm{Cu}-\mathrm{Fe} / \mathrm{Cu}^{*}$} & \multicolumn{3}{|c|}{$\mathrm{Cu}-\mathrm{Fe} / \mathrm{Cu}^{*}$} \\
\hline & $\mathrm{CN}$ & $\Delta_{\mathrm{CN}-\mathrm{AD}}$ & $\Delta_{\mathrm{CN}-\mathrm{RT}}$ & $\mathrm{R}(\AA)$ & $o^{2}\left(\AA^{2}\right)$ & $\mathrm{CN}$ & $\Delta_{\mathrm{CN}-\mathrm{AD}}$ & $\Delta_{\mathrm{CN}-\mathrm{RT}}$ & $\mathrm{R}(\AA)$ & $\mathrm{CN}$ & $\Delta_{\mathrm{CN}-\mathrm{AD}}$ & $\Delta_{\mathrm{CN}-\mathrm{RT}}$ & $\mathrm{R}(\AA)$ & $\mathrm{CN}$ & $\Delta_{\mathrm{CN}-\mathrm{AD}}$ & $\Delta_{\mathrm{CN}-50 \mathrm{C}}$ \\
\hline $75 \mathrm{C} 96 \mathrm{~h} \mathrm{~A}$ & $3.0(3)$ & & & $1.96(1)$ & $.004 *$ & $1.2(4)$ & & & $3.00(3)$ & - & & & - & $1.1(8)$ & & \\
\hline 50C 96h A & $3.7(3)$ & & & 1.94(1) & $.004 *$ & $1.8(8)$ & & & $3.06(3)$ & $1.6(9)$ & & & $3.24(5)$ & $1.2(8)$ & & \\
\hline 50C 96h D & $3.7(2)$ & $0 \%$ & $19 \%$ & $1.95(1)$ & $.004 *$ & $2.1(6)$ & $17 \%$ & $0 \%$ & $3.05(2)$ & $2.1(7)$ & $31 \%$ & $10 \%$ & $3.28(3)$ & $0.6(6)$ & $-50 \%$ & - \\
\hline RT 96h A & $3.4(2)$ & & & $1.94(1)$ & $.004 *$ & $1.9(6)$ & & & $3.04(3)$ & $1.6(7)$ & & & $3.27(3)$ & - & & \\
\hline RT 96h D & $3.1(2)$ & $-9 \%$ & - & $1.95(1)$ & $.004 *$ & $2.1(5)$ & $11 \%$ & - & $3.04(2)$ & $1.9(6)$ & $19 \%$ & - & $3.27(2)$ & - & - & - \\
\hline
\end{tabular}

Note: Standard deviations at a 95\% confidence level ( \pm 20 ) are listed in parentheses.

$\mathrm{CN}$ : coordination number, $\bullet_{\mathrm{CN}-\mathrm{AD}}$ : change in coordination number when comparing adsorbed to desorbed spectra, $\bullet_{\mathrm{CN}-\mathrm{RT}}:$ change in coordination number relative to the room temperature sample, ${ }_{\mathrm{CN}-50 \mathrm{C}}$ : change in coordination number relative to the $50^{\circ} \mathrm{C}$ sample, $\mathrm{R}$ : interatomic distance, and ${ }^{2}$ : Debye-Waller factor. $\mathrm{S}_{0}=0.9 ; \mathrm{E}_{0}$ values ranged from -9.5 to $-16.4 \mathrm{eV}$.

"Value of $o^{2}$ fixed at $0.01 \AA^{2}$ in least-squares refinement. 
Table 4.

\begin{tabular}{|c|c|c|c|c|c|c|c|c|c|c|}
\hline \multirow{2}{*}{ Sample } & \multicolumn{4}{|c|}{$\mathrm{Cu}-\mathrm{O}$} & \multicolumn{3}{|c|}{$\mathrm{Cu}-\mathrm{Fe} / \mathrm{Cu}^{*}$} & \multicolumn{3}{|c|}{$\mathrm{Cu}-\mathrm{Fe} / \mathrm{Cu}^{*}$} \\
\hline & $\mathrm{CN}$ & ${ }_{\mathrm{CN}-\mathrm{Ohr}}$ & $\mathrm{R}(\AA)$ & $\sigma^{2}\left(\AA^{2}\right)$ & $\mathrm{CN}$ & CN- $-\mathrm{hr}$ & $\mathrm{R}(\AA)$ & $\mathrm{CN}$ & CN-Ohr & $\mathrm{R}(\AA)$ \\
\hline RT 96h D & $3.1(2)$ & $30 \%$ & $1.95(1)$ & $.004 *$ & $2.1(5)$ & $75 \%$ & $3.04(2)$ & $1.9(6)$ & $19 \%$ & $3.27(2)$ \\
\hline RT 72h D & $3.9(3)$ & $70 \%$ & $1.94(1)$ & $.004 *$ & $2.0(7)$ & $67 \%$ & $3.04(3)$ & $1.7(9)$ & $6 \%$ & $3.27(4)$ \\
\hline RT 48h D & $3.6(4)$ & $57 \%$ & $1.94(2)$ & $.004 *$ & $2.0(1.1)$ & $67 \%$ & $3.03(4)$ & $1.8(1.4)$ & $13 \%$ & $3.27(4)$ \\
\hline RT 24h D & $3.8(2)$ & $65 \%$ & $1.93(1)$ & $.004 *$ & $2.0(6)$ & $67 \%$ & $3.03(2)$ & $1.8(8)$ & $13 \%$ & $3.27(3)$ \\
\hline RT 12h D & $3.2(2)$ & $39 \%$ & $1.95(1)$ & $.004 *$ & $1.4(5)$ & $17 \%$ & $3.05(4)$ & $1.2(6)$ & $-25 \%$ & $3.24(6)$ \\
\hline RT 6h D & $3.2(2)$ & $39 \%$ & $1.95(1)$ & $.004 *$ & $1.2(6)$ & $0 \%$ & $3.03(5)$ & $1.2(7)$ & $-25 \%$ & $3.22(6)$ \\
\hline RT 4h D & $2.9(2)$ & $26 \%$ & $1.96(1)$ & $.004 *$ & $1.4(5)$ & $17 \%$ & $3.08(3)$ & $1.4(6)$ & $-13 \%$ & $3.28(4)$ \\
\hline RT Oh D & $2.3(3)$ & - & $1.98(2)$ & $.004 *$ & $1.2(8)$ & - & $3.06(6)$ & $1.6(9)$ & - & $3.26(4)$ \\
\hline
\end{tabular}

Note: Standard deviations at a $95 \%$ confidence level $( \pm 2 \sigma$ are listed in parentheses.

$\mathrm{CN}$ : coordination number, ${ }_{\mathrm{CN}-\mathrm{Ohr}}$ : change in coordination number relative to the 0-hour sample, R: interatomic distance, and ${ }^{2}$ :

Debye-Waller factor. $\mathrm{S}_{0}=0.9 ; \mathrm{E}_{0}$ values ranged from -9.5 to $-13.4 \mathrm{eV}$.

"Value of $o^{2}$ fixed at $0.01 \AA^{2}$ in least-squares refinement. 


\section{Figure Captions}

Figure 1. TEM images of a) control monodispersed nanoparticles (minor aggregation likely due to drying on the TEM substrate); b) nanoparticles aged at $75^{\circ} \mathrm{C}$ for 96 hours; c) nanoparticles aged at $75^{\circ} \mathrm{C}$ for 96 hours in the presence of $0.5 \mathrm{mM} \mathrm{Zn}$ (II); and d) nanoparticles aged at $75^{\circ} \mathrm{C}$ for 96 hours in the presence of $0.5 \mathrm{mM} \mathrm{Cu}(\mathrm{II})$.

Figure 2. Synchrotron micro-X-ray diffraction patterns of nanoparticles aged at $78{ }^{\circ} \mathrm{C}$ for periods of time up to 96 hours (time interval between patterns is $8 \mathrm{hrs}$ ) in the presence of a) $0.5 \mathrm{mM} \mathrm{Zn(II)} \mathrm{or} \mathrm{b)} 0.5 \mathrm{mM} \mathrm{Cu}$ (II). Excerpted from (KIM et al., 2008).

Figure 3. Combined results from dynamic light scattering (DLS) (dashed lines) and BET surface area measurements (solid lines) of aged iron oxyhydroxide nanoparticles, showing an inverse relationship between average particle diameter and reactive surface area.

Figure 4. Percentage $\mathrm{Zn}$ (II) uptake/retention as a function of time after the adsorption step (open symbols) and following the desorption step (solid symbols).

Figure 5. Zn K-edge EXAFS spectra and Fourier transforms of corresponding Zn adsorbed and desorbed samples aged at $75^{\circ} \mathrm{C}$ for 4,24 , and 96 hours (black = raw data, gray $=$ fit). Table 1 lists the corresponding fitting values.

Figure 6. Schematic representation of potential metal ion sorption complexes associated with nanoparticle aggregates. For simplicity, in most cases the coordinating oxygen ions are not shown around the metal cations. Shown are, in generally increasing order of expected binding strength: a) outer-sphere complex; b) monodentate complex; c) bidentate edge-sharing complex; d) bidentate corner-sharing complex to disordered site; e) bidentate corner-sharing complex to ordered site; f) tridentate corner-sharing dimer complex; g) bidentate edge-sharing complex located within interparticle nanopore space; h) bidentate corner-sharing complex located within interparticle nanopore space; i) dimer complex located within interparticle nanopore space; and j) lattice-substituted cation. Modified from Gilbert et al. (2009).

Figure 7. Zn K-edge EXAFS spectra and Fourier transforms of desorbed samples aged for 96 hours at room temperature $\left(\sim 20^{\circ} \mathrm{C}\right), 50^{\circ} \mathrm{C}$, and $75^{\circ} \mathrm{C}$ (black $=$ raw data, gray $=$ fit $)$. Table 2 lists the corresponding fitting values.

Figure 8. Percentage $\mathrm{Cu}(\mathrm{II})$ uptake/retention as a function of time after the adsorption step (open symbols) and following the desorption step (solid symbols).

Figure 9. $\mathrm{Cu}$ K-edge EXAFS spectra and Fourier transforms of corresponding adsorbed and desorbed samples aged for 96 hours at room temperature, $50^{\circ} \mathrm{C}$, and $75^{\circ} \mathrm{C}$ (black $=$ raw data, gray $=$ fit). Table 3 lists the corresponding fitting values. 
Figure 10. Cu K-edge EXAFS spectra and Fourier transforms of desorbed samples aged from 096 hours at room temperature $($ black $=$ raw data, gray $=$ fit). Table 4 lists the corresponding fitting values.

Figure 11. Schematic showing effects of aggregation pathway on a number of variables, comprising results from this two-part study and a previous work (DALE et al., 2014 (submitted); GILBERT et al., 2009).
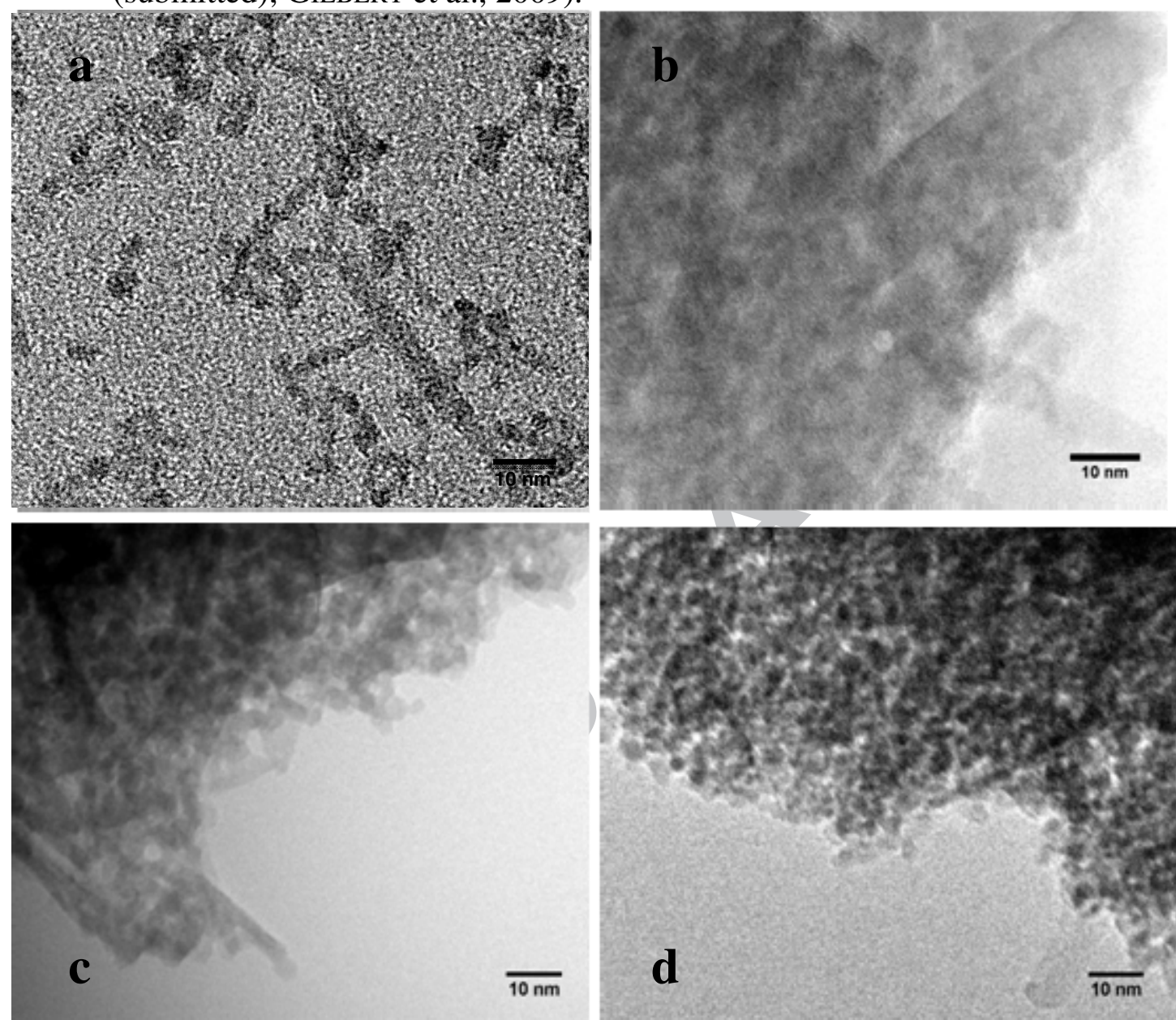

Figure 1. 

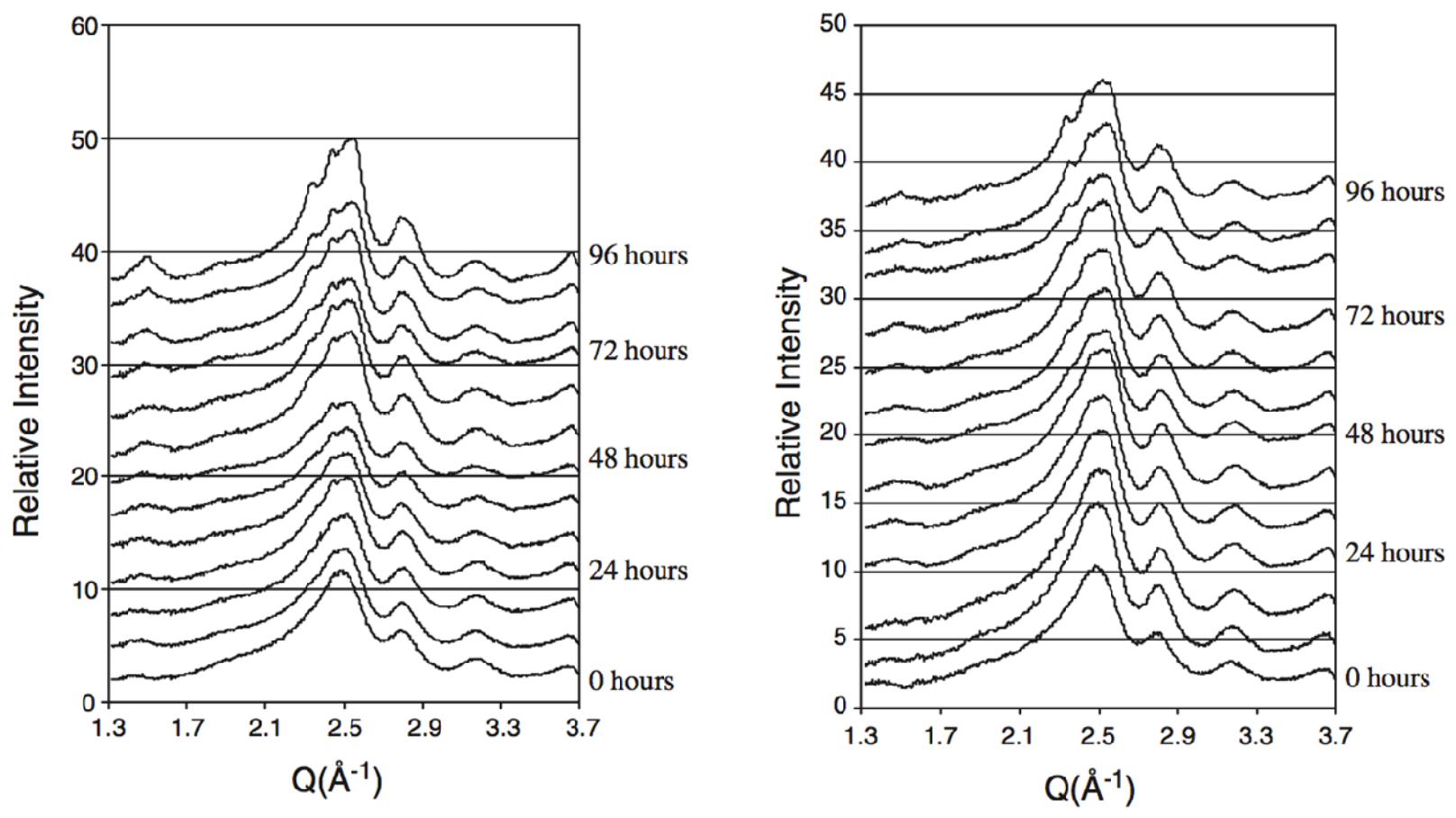

Figure 2. 


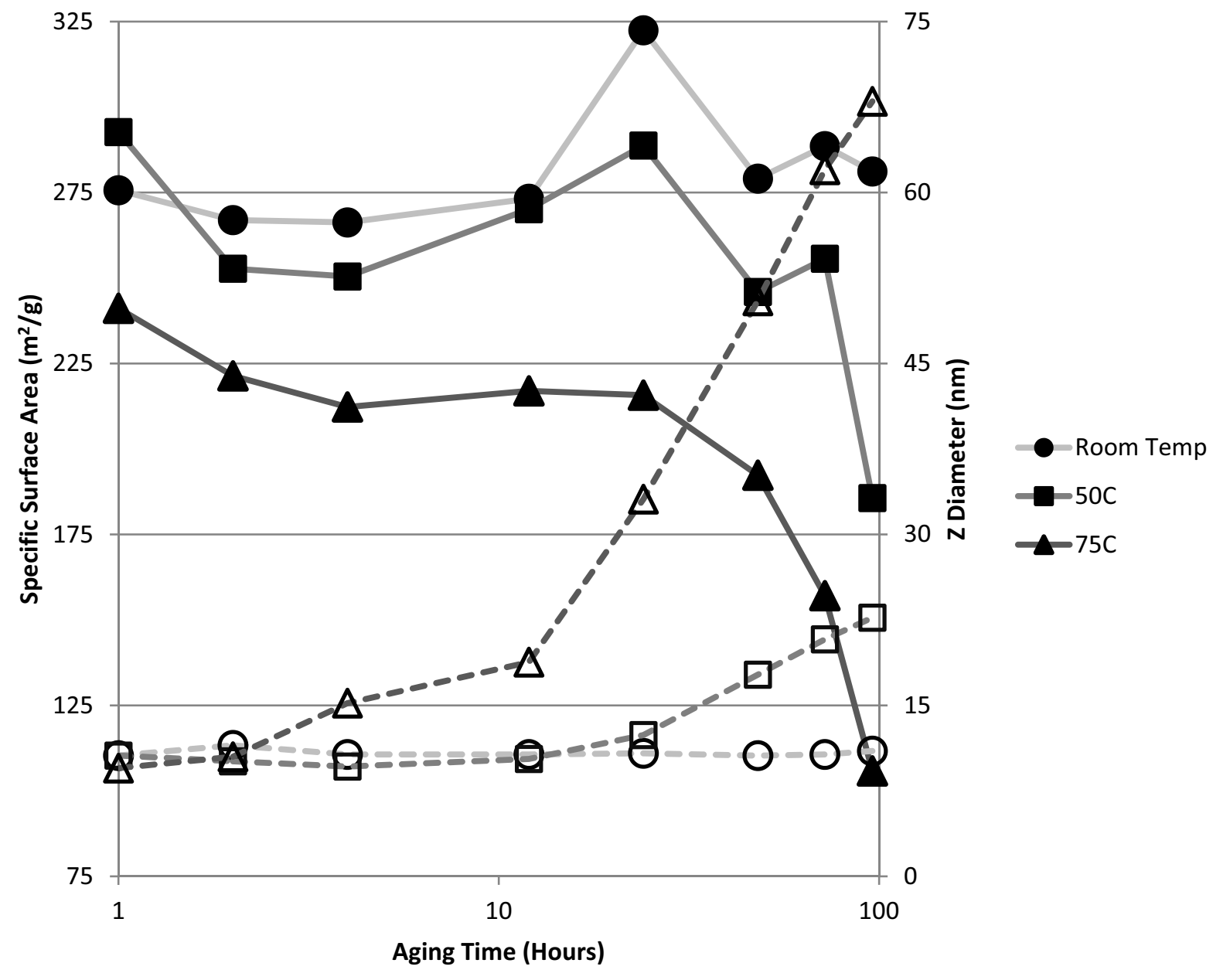

Figure 3. 


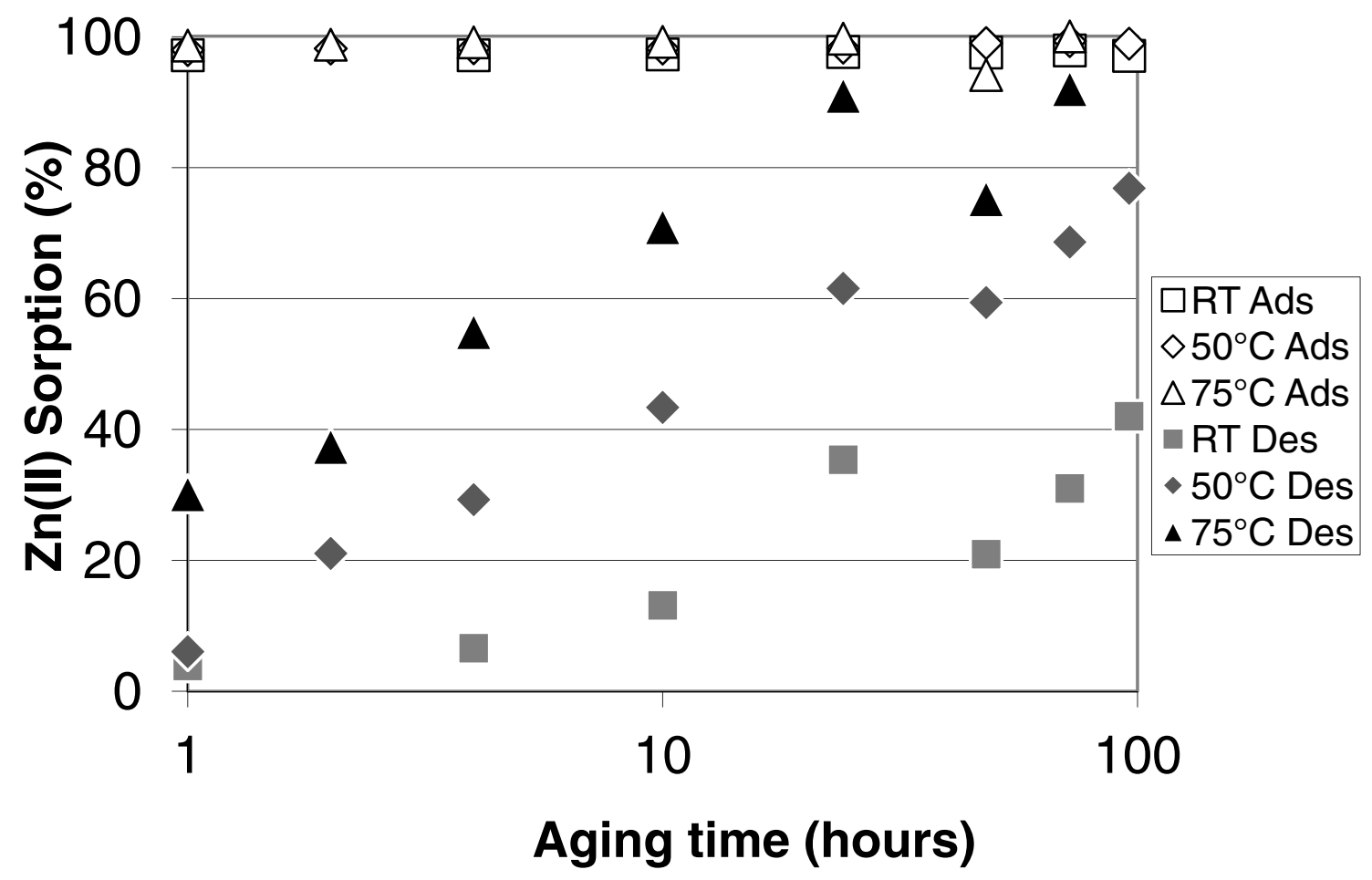

Figure 4. 

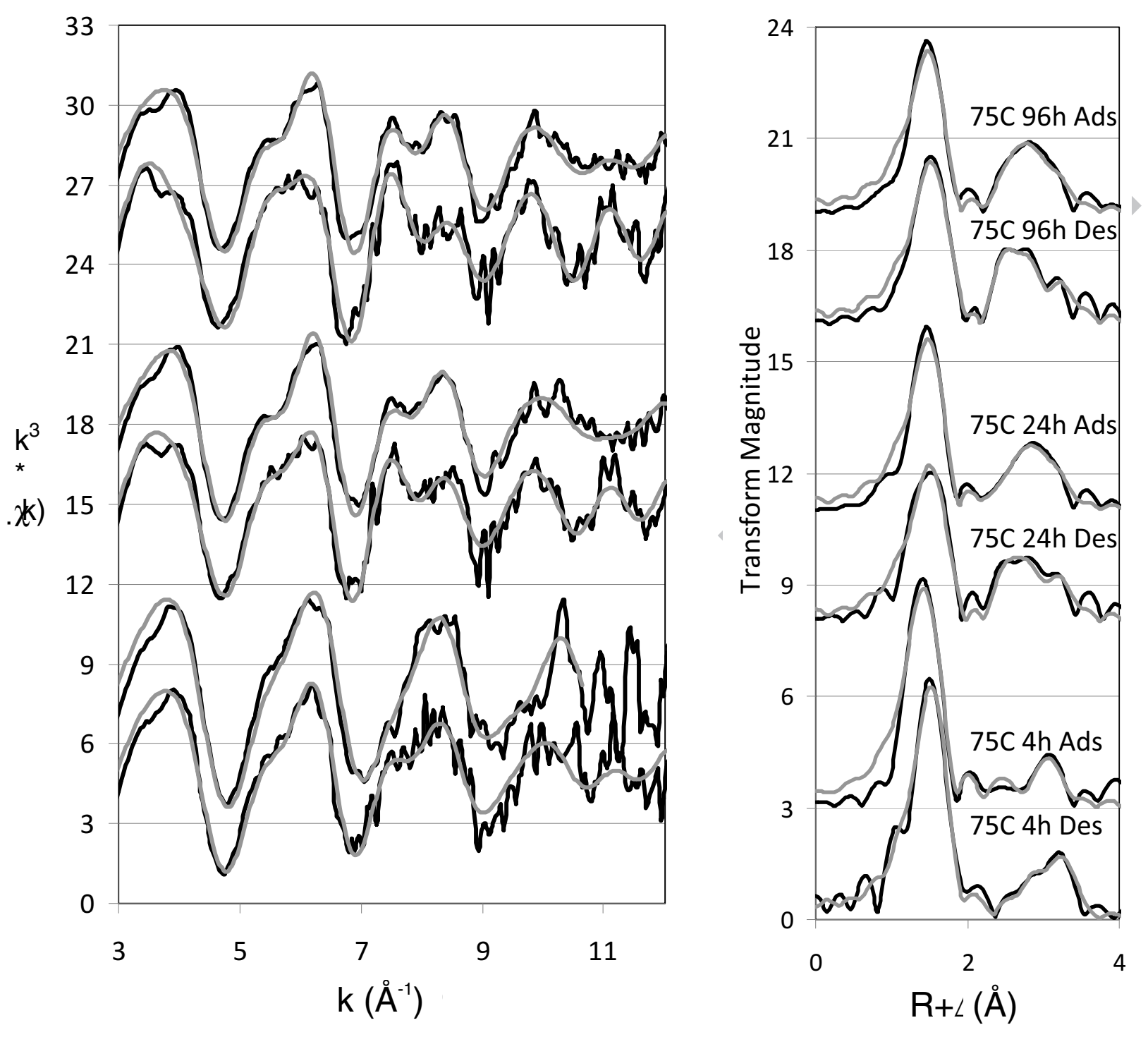

Figure 5. 


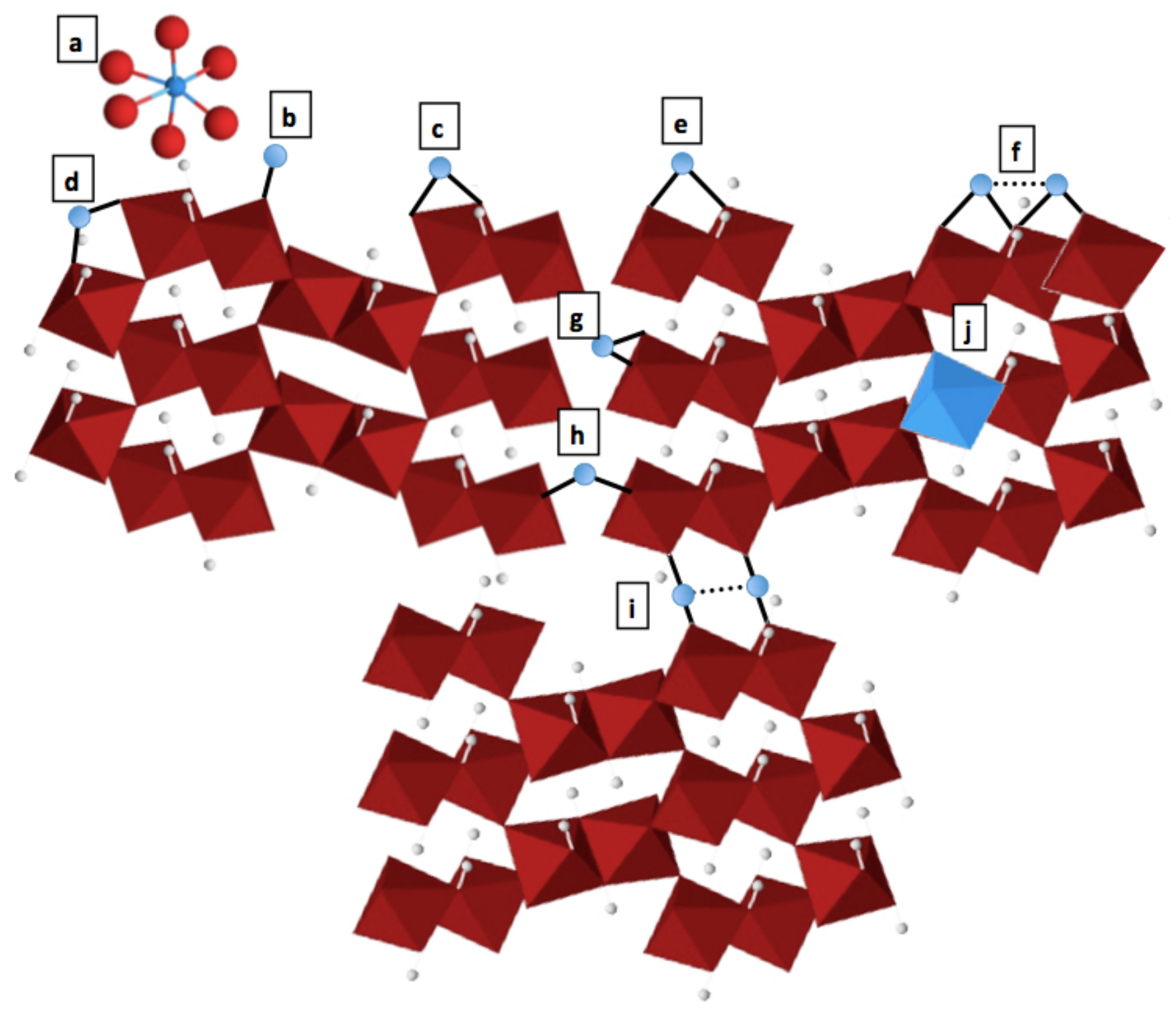

Figure 6. 

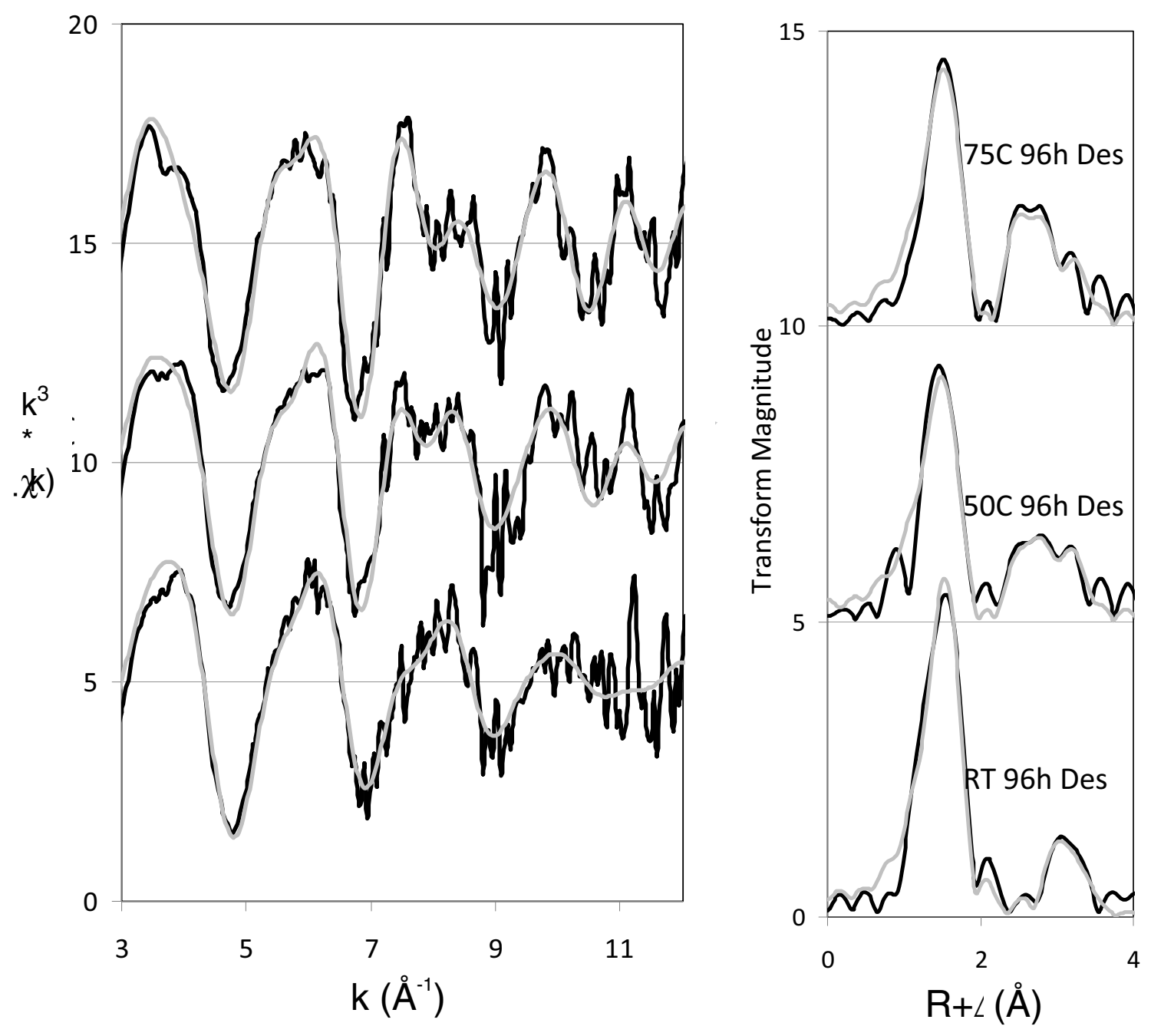

Figure 7. 


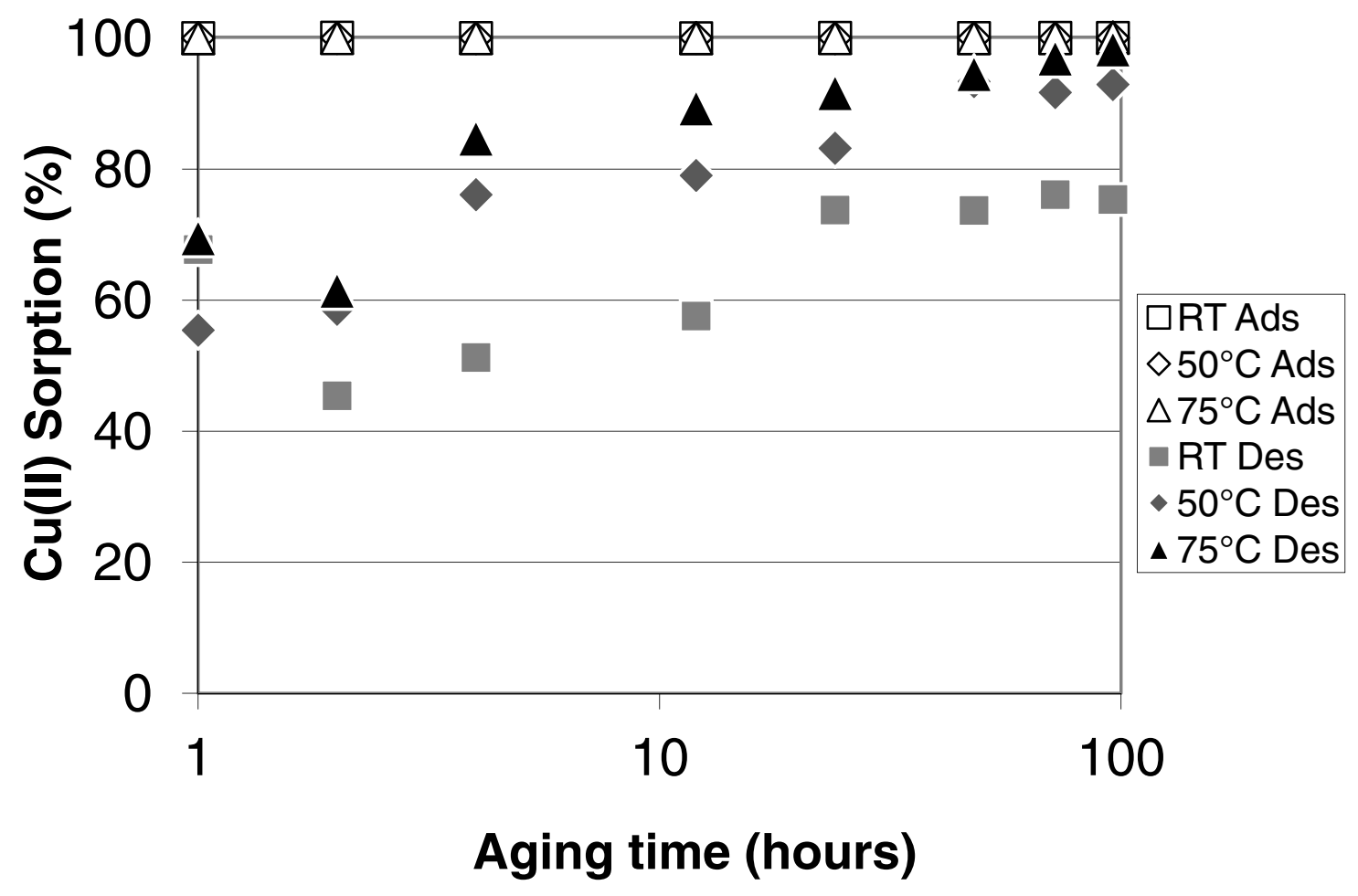

Figure 8. 

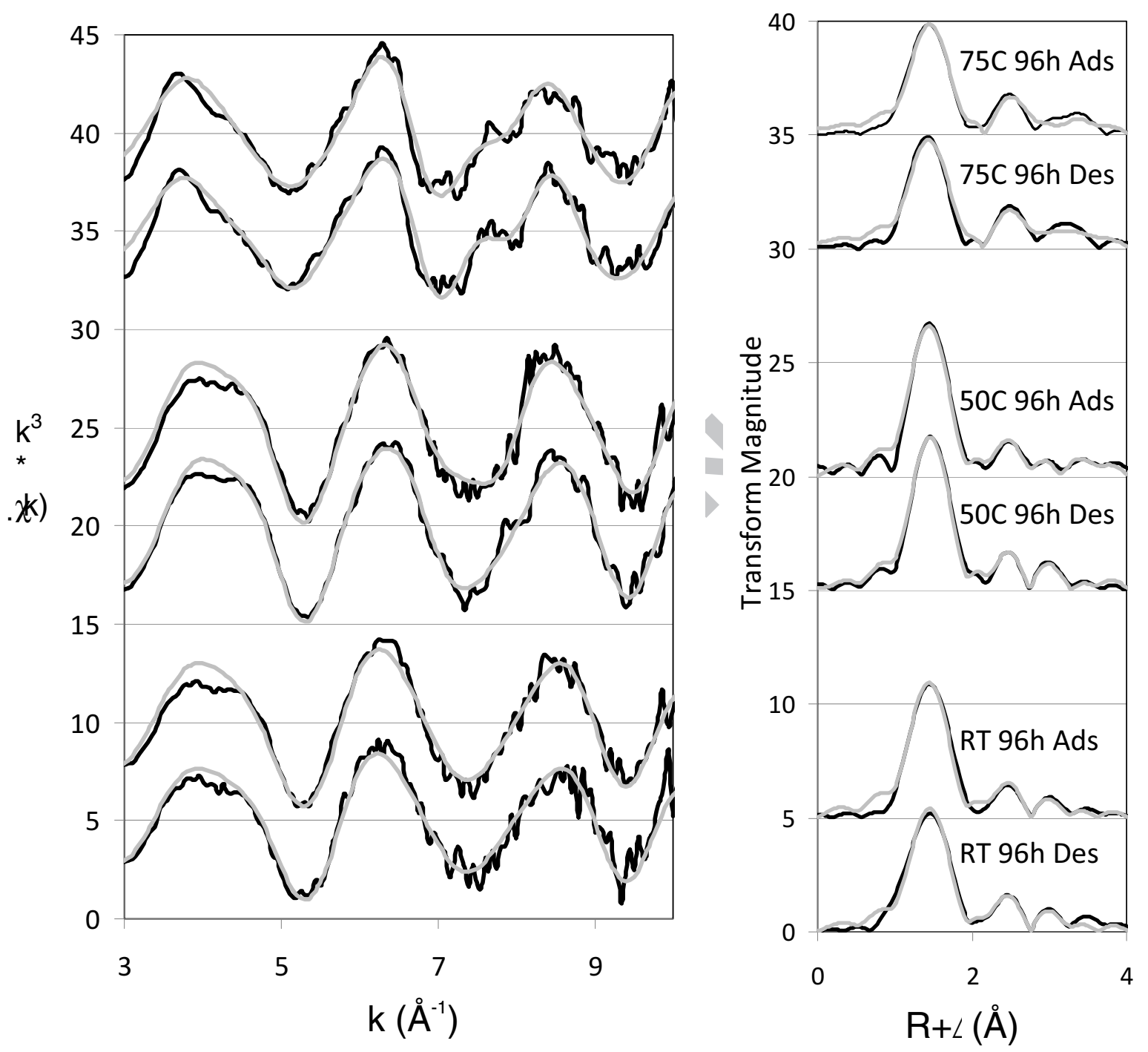

Figure 9. 

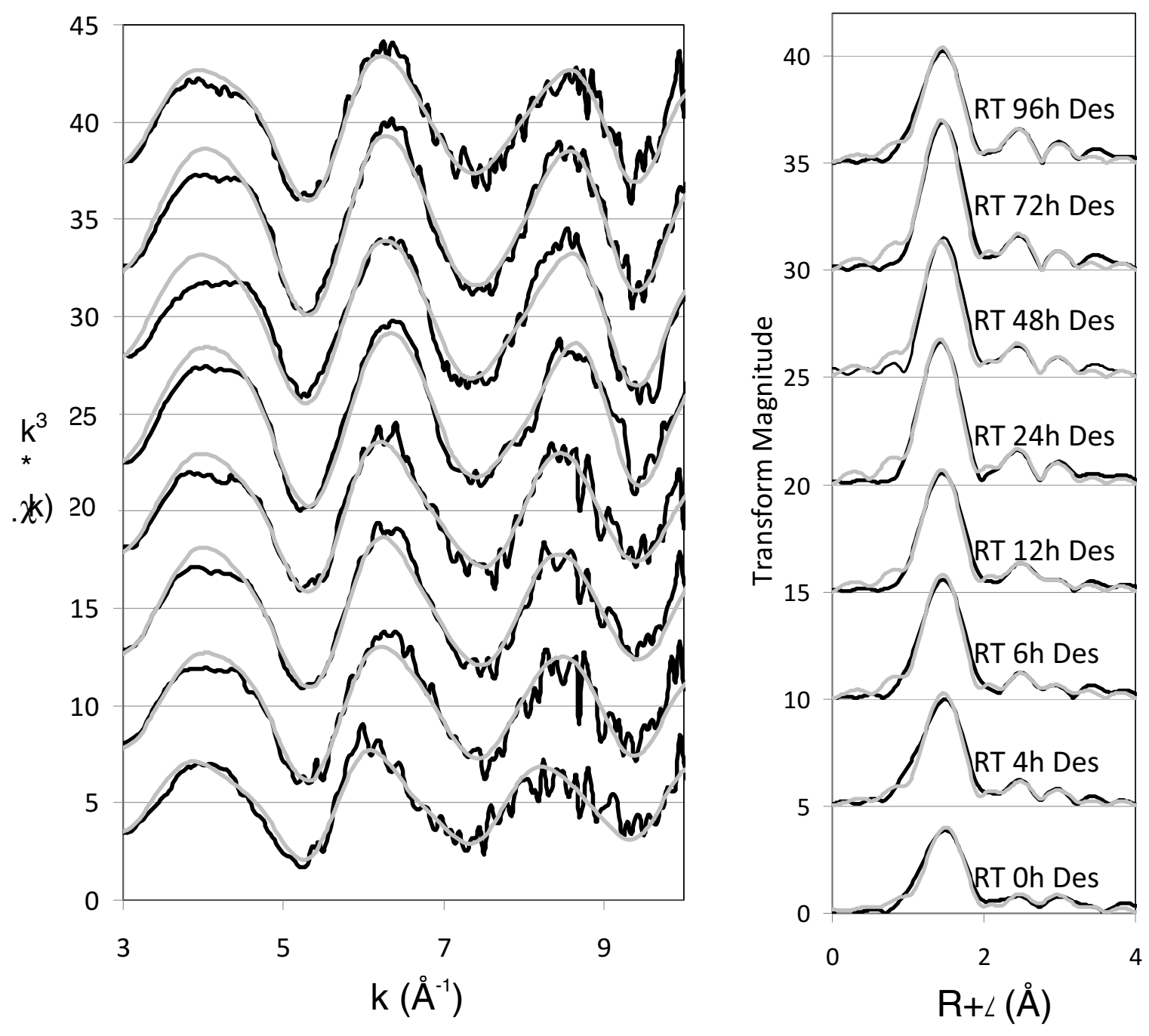

Figure 10. 


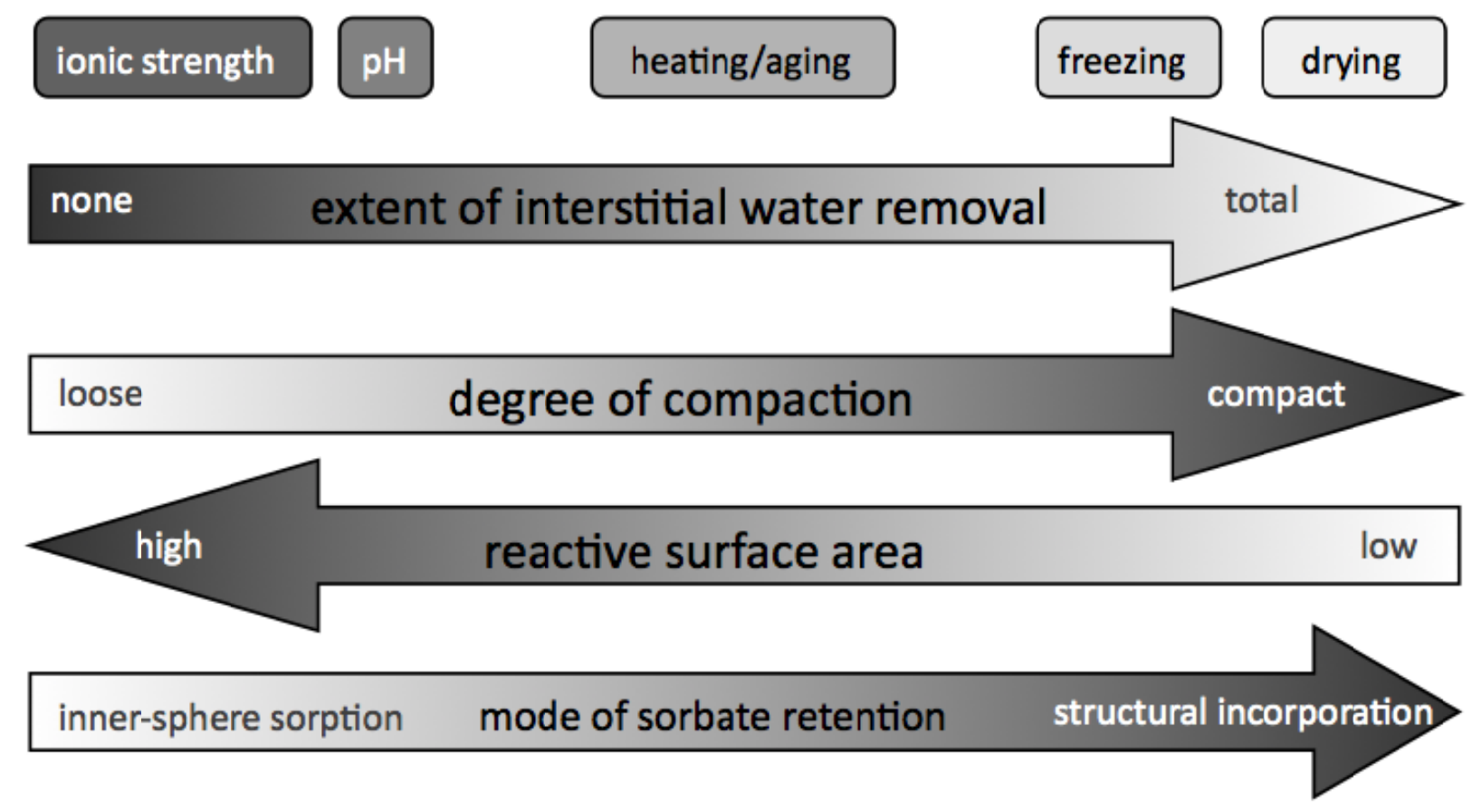

Figure 11. 